Atmos. Chem. Phys., 18, 11863-11884, 2018

https://doi.org/10.5194/acp-18-11863-2018

(C) Author(s) 2018. This work is distributed under

the Creative Commons Attribution 4.0 License.

\title{
Wildfires as a source of airborne mineral dust - revisiting a conceptual model using large-eddy simulation (LES)
}

\author{
Robert Wagner $^{1}$, Michael Jähn ${ }^{1, a}$, and Kerstin Schepanski ${ }^{1}$ \\ ${ }^{1}$ Leibniz Institute for Tropospheric Research (TROPOS), Leipzig, Germany \\ ${ }^{a}$ now at: Swiss Federal Laboratories for Material Science and Technology (Empa), Dübendorf, Switzerland
}

Correspondence: Robert Wagner (robert.wagner@tropos.de)

Received: 21 December 2017 - Discussion started: 27 April 2018

Revised: 26 July 2018 - Accepted: 3 August 2018 - Published: 20 August 2018

\begin{abstract}
Airborne mineral dust is a key player in the Earth system and shows manifold impacts on atmospheric properties such as the radiation budget and cloud microphysics. Investigations of smoke plumes originating from wildfires found significant fractions of mineral dust within these plumes - most likely raised by strong, turbulent firerelated winds. This study presents and revisits a conceptual model describing the emission of mineral dust particles during wildfires. This is achieved by means of high-resolution large-eddy simulation (LES), conducted with the All Scale Atmospheric Model (ASAM). The impact of (a) different fire properties representing idealized grassland and shrubland fires, (b) different ambient wind conditions modulated by the fire's energy flux, and (c) the wind's capability to mobilize mineral dust particles was investigated. Results from this study illustrate that the energy release of the fire leads to a significant increase in near-surface wind speed, which consequently enhances the dust uplift potential. This is in particular the case within the fire area where vegetation can be assumed to be widely removed and uncovered soil is prone to wind erosion. The dust uplift potential is very sensitive to fire properties, such as fire size, shape, and intensity, but also depends on the ambient wind velocity. Although measurements already showed the importance of wildfires for dust emissions, pyro-convection is so far neglected as a dust emission process in atmosphere-aerosol models. The results presented in this study can be seen as the first step towards a systematic parameterization representing the connection between typical fire properties and related dust emissions.
\end{abstract}

\section{Introduction}

\subsection{Occurrence and characteristics of wildfires}

Biomass burning and other types of natural and prescribed wildland fires (in the following referred to altogether as wildfires) are very common in semiarid regions almost all over the world. In particular, tropical savannas, shrublands, grasslands, croplands, and rain forests are frequently burned ecosystems during dry seasons or under drought conditions (e.g., Gatebe et al., 2014; Roberts et al., 2009). The overwhelming majority of these fires are caused by human activity such as fire clearing of natural landscapes for agriculture and domestic uses (Haywood et al., 2008).

The vulnerability of a landscape to wildfires in general and the destructiveness of fires depend strongly on the local climatic conditions and predominant weather regimes. A necessary condition for the development of a fire is the availability of a sufficient amount of biofuel (biomass). The higher the fuel load, the stronger the fire that can develop. Grassland and shrubland fires are usually smaller in size and intensity compared to forest fires, for which the typical forest vegetation provides a higher fuel load, resulting in a higher energy consumption by the fire (Reid et al., 2005). Although a greener and denser vegetation may provide more biofuel, the higher moisture content counteracts the fire risk. Compared to this, dry vegetation provides a lower fuel load; however, it is much more vulnerable to fire ignition.

Wildfires have large impacts on the environment via altering of atmospheric and surface properties. The heat of the fire and the corresponding fire updraft result in a major disturbance in the tropospheric wind and temperature fields (Clements et al., 2008). Furthermore, fires strongly im- 
pact the surface properties in the fire-affected area, which can change the vulnerability of that area to wind erosion during and after the fire. The fire consumes the vegetation cover quite effectively; however, the completeness of the removal also depends on the fire intensity. Especially in the case of low-intensity fires, trees and shrubs can resist the fire whereas the ground-covering plants and organic matter are usually completely removed (e.g., McNabb and Swanson, 1990; Levin et al., 2012). Other effects of fires on soil surfaces which were observed during prescribed and natural fires include changes in mineralogy, texture, porosity, grain size distribution, and water capability of the soils (e.g., Atanassova and Doerr , 2011; McNabb and Swanson, 1990; Pérez-Cabello et al., 2006). In the case of high-intensity fires, an aggregation of finer particles such as clay minerals to larger particles such as silt and sand was found (Giovannini et al., 2001; McNabb and Swanson, 1990; Albalasmeh et al., 2013). In contrast, also during such high-intensity fires a breakdown of soil structures and crusts was observed, which would increase the number of fine particles available for mobilization (McNabb and Swanson, 1990; Levin et al., 2012). Thus, it appears that fires can lead to quite effective conditions for the mobilization of soil and dust particles. The higher vulnerability of burned landscapes to dust emission was also found by other studies (e.g., Whickler et al., 2002, 2006; Ravi et al., 2012; Merino-Martín et al., 2014), suggesting this as a possible important source of airborne mineral dust.

\subsection{Emission of mineral dust}

The emission of mineral dust into the atmosphere is primarily a wind-driven process and can be considered a threshold problem (e.g., Marticorena and Bergametti, 1995). To uplift dust particles from the ground and entrain them into the atmosphere, the internal cohesive forces and binding energies among the soil particles as well as gravitational forces have to be overcome by the energy supplied by the wind drag (e.g., Kok et al., 2012; Bagnold, 1941). The amount of energy necessary to mobilize soil particles depends on parameters such as soil moisture, soil texture, grain size, and vegetation cover (e.g., Shao, 2001). Consequently, a threshold wind speed has to be exceeded in order to set particles into motion.

However, there are different modes of dust entrainment into the atmosphere. The most common approach is the socalled saltation process, which can be considered a quite important and relatively well-established approach for strong dust emission events in particular. Here, the wind drag first mobilizes particles with a size of around $70 \mu \mathrm{m}$, resulting in a "jumping" along the surface. This enables even smaller particles $(<70 \mu \mathrm{m})$ to be entrained into the atmosphere (suspension). Supported by wind tunnel experiments and field measurements, typical threshold values of wind speed needed for dust emission to occur lie in the range between 6 and $7 \mathrm{~m} \mathrm{~s}^{-1}$ (e.g., Kalma et al., 1988; Gilette, 1978). Despite the dust en- trainment via saltation, other processes can also be relevant for dust injection into the atmosphere. This involves direct aerodynamic lifting via turbulent eddies, which can be an important mechanism, especially under weak ambient wind conditions as well as in the case of microscale emission phenomena (Klose and Shao, 2012, 2013). Here, the convective turbulent lifting of dust can also occur under conditions in which the horizontal wind velocities are too small to initialize saltation (Loosmore and Hunt, 2000). Using largeeddy simulation (LES), Klose and Shao (2013) showed that turbulent dust emissions are enhanced along convergence lines with updrafts, within downdraft areas, and in vortices. As these are typical features observed in fire-induced wind fields, turbulent dust emission is likely to contribute to firedriven dust emissions.

\subsection{Dust emissions related to wildfires}

As already stated, fire impacts on the soil and surface conditions and the lower tropospheric circulation can lead to conditions that are favorable for dust emissions. Thus, it is not surprising that several studies found enhanced fractions of mineral dust particles or rather enhanced concentrations of typical soil tracer species within smoke plumes originating from different fire types in different areas of the world (e.g., Nisantzi et al., 2014; Kavouras et al., 2012; Diapouli et al., 2014; Maudlin et al., 2015; Alves et al., 2010; Pio et al., 2008). For example, Nisantzi et al. (2014) found dust fractions in the smoke plumes varying between $50 \%$ for fresh plumes with an age of approximately 1 day and $10 \%$ for aged plumes with an atmospheric lifetime greater than 4 days. The corresponding mass fraction varies between $25 \%$ (aged plumes) and $80 \%$ (fresh plumes), which is mainly related to coarse-mode dust particles (particle diameter $>500 \mathrm{~nm}$ ), which are removed during the atmospheric transport of the plume due to gravitational settling. A dominance of coarsemode dust particles was also found with ground-based in situ measurements near fire locations (Gaudichet et al., 1995; Maenhaut et al., 1996). Both studies found a significant increase in the concentration and the mean size of typical mineral dust elements and soil particles, mostly clay and some feldspar minerals in a size range of several micrometers in fire-related samples compared to non-fire background samples. By investigating prescribed fires in desert regions in the western US, Kavouras et al. (2012) found that more than $10 \%$ of the $\mathrm{PM}_{10}$ fire emissions can be linked to a resuspension of soil particles related to the high turbulent fire winds. The ability of the strongly enhanced turbulence and wind velocities in and nearby the fire to uplift soil and dust particles was already highlighted by Palmer (1981) and Susott et al. (1991), and these modulations of the wind patterns are able to raise even supergiant particles with a size of up to $1 \mathrm{~mm}$ and larger consisting of ash and soil remains (Radke, 1991). The high fire activity in arid and semiarid regions can lead to an amount of fire-related dust emission, which could be sig- 
nificant on a global scale (Kavouras et al., 2012). Schlosser et al. (2017) investigated the aerosol composition of western US wildfire plumes and found significantly enhanced levels of fine soil components and coarse-mode dust particles from crustal origin within these plumes. An exemplary model simulation, performed with a global aerosol model, could not capture the increased dust emission during the fires since these models were not designed to resolve the small-scale processes responsible for dust uptake in wildfires.

Based on these findings, we have developed a conceptual model of the entrainment of mineral dust particles into the atmosphere via the pyro-convective updraft as illustrated in Fig. 1. The fire radiative energy released by the combustion of the vegetation heats the near-surface air layers strongly. The heated air begins to rise and eventually a convective updraft forms. This upward motion can result in a significant pressure drop of the order of up to $1 \mathrm{hPa}$ at the surface within or near the fire center (Clements et al., 2008). Subsequently, a zone of strong convergence forms and surrounding air flows towards the fire, replacing the rising air. Since the ascent of the heated air above the fire area occurs quite rapidly, a strong acceleration of the horizontal near-surface winds into the fire updraft region is established, accompanied by significantly increased turbulence, enhanced vortices, and possible increasing wind shear within the boundary layer (Chalbot et al., 2013; Clements et al., 2008). Together with the removal of vegetation during the burning process and the accompanied dehydration and modification of the soil, the resulting accelerated horizontal winds and the increased level of atmospheric turbulence appears to be able to mobilize soil and dust particles. Depending on the acting buoyancy forces balancing the particles' gravitation, the mobilized dust particles may reside in the atmosphere long enough to be further lifted up by the updraft motion and may mix with the combustion aerosols. Depending on the strength of the updrafts and the atmospheric background conditions, the dust particles may also be injected into higher atmospheric levels above the planetary boundary layer (PBL). Reaching the free atmosphere, long-distance transport of the particles by the general atmospheric circulation can become possible, accompanied by increased impacts on the atmospheric properties (Amiridis et al., 2010; Nisantzi et al., 2014; Ansmann et al., 2009). However, Veira et al. (2015) showed that up to $50 \%$ of the fire plumes remain in the PBL and do not reach the free atmosphere.

Despite the mobilization of dust particles from the ground, an additional source for dust particles emitted during wildfires are dust particles deposited on the vegetation during previous dust events. This aspect may apply to wildfires occurring in desert margin regions such as the Sahel. During combustion, these particles can be mixed directly into the heated updraft and contribute to the dust load of the smoke plume (Paris et al., 2010; Cachier et al., 1995).

The strength and efficiency of dust entrainment during wildfires depend on several aspects, of which fire proper- ties, soil conditions, and the state of the atmosphere appear to be the most important. Fire properties such as fire size, shape, intensity, and spreading rate determine the strength of the heated updraft and consequently the strength of convergence, the triggered turbulence around the fire, and finally the strength of the accelerated horizontal winds and their gustiness.

Although some studies indicate the importance of such wildfires to the atmospheric dust load, the process of the dust uplift during such fire events is not well understood so far and currently not considered as a source of airborne mineral dust in climate or aerosol models. This is all the more astonishing since the mixture of raised dust particles with fresh combustion aerosol such as soot or black carbon can lead to changes in the chemical, optical, and microphysical properties of the dust particles. This would have impacts on the particle aging processes, the dust-radiative forcing, and the suitability of dust particles to act as ice nuclei particles (INPs) or as cloud condensation nuclei (CCN), which finally influence atmospheric residence time and microphysical properties of clouds and are related to health hazards (e.g., Chalbot et al., 2013; Hand et al., 2010; McCluskey et al., 2014; Levin et al., 1996; Winton et al., 2016).

\subsection{Use of LES to resolve fire dynamics}

This study aims to revisit the above introduced conceptual model of mineral dust particle entrainment during fire events (see Sect. 1.3 and Fig. 1). To achieve this, models with a high spatial and temporal resolution are essential to describe the acting forces and small-scale processes responsible for firerelated dust emissions (Schlosser et al., 2017). A suitable tool is LES, which is able to resolve turbulent atmospheric motions and allows for detailed process studies in an idealized setup, to test hypotheses, and to investigate connections among small-scale effects.

In this context, LES is commonly used to simulate fire behaviors in different fields of application. Most of these high-resolution model studies aim to understand the spread of wildfires as a function of fuel consumption and ambient atmospheric forces to allow for a better prediction of the fire spreading, primarily to support strategies to extinguish and limit the fires (e.g., Sun et al., 2009; Mell et al., 2008; Morvan, 2009; Cunningham and Linn, 2007; Linn and Cunningham, 2005). In these cases a feedback between fire and atmosphere within the model is necessary, which takes into account the complex interaction among the fire behavior, the burning vegetation (availability of biofuel), and its environment as is carried out in the WRF-Fire model (Coen et al., 2013) for example. However, this study aims to investigate the impacts of fire-induced disturbances on the near-surface wind fields and consequent potential for dust mobilization only, which allows a reduced complexity applied in this first approach. This means that only fire effects on the atmosphere 


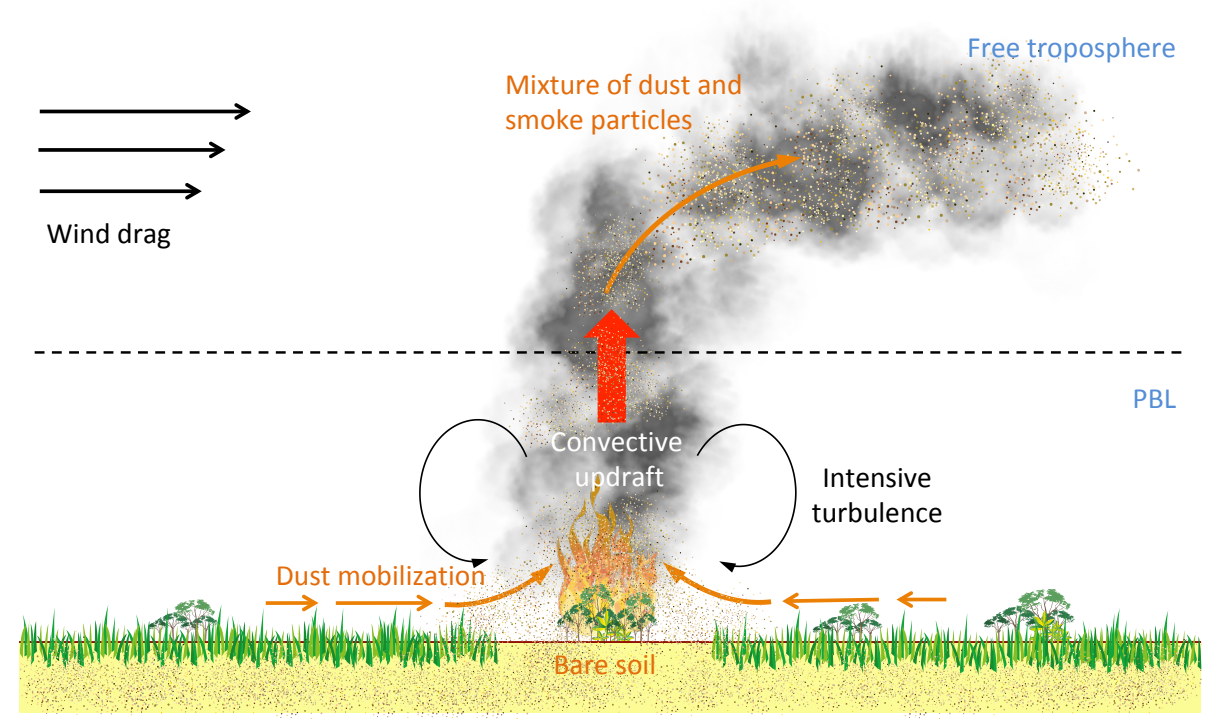

Figure 1. Schematic overview of the conceptual model of fire-driven emissions of mineral dust.

but not the feedback of the atmosphere on the fire need to be considered.

This paper is structured as follows: Sect. 2 describes the general model setup and the application to the fire simulations. Section 3 deals with the performed case studies and their representativeness for real wildfires. In Sect. 4, the results are presented; this means in particular the impacts of the fires on the near-surface wind dynamics for different case simulations are shown and compared to each other. Section 5 discusses the results in a broader context with respect to the dust emission potential. The conclusion closes the paper.

\section{Fire simulations with the All Scale Atmospheric Model (ASAM)}

The All Scale Atmospheric Model (ASAM; Jähn et al., 2015, 2016) is a numerical solver developed at the Leibniz Institute for Tropospheric Research (TROPOS), in Leipzig, Germany. ASAM can be used for atmospheric applications over a wide range of scales. It solves the three-dimensional, fully compressible Euler equations. Different time integration schemes are available, e.g., a split-explicit RungeKutta scheme (Knoth and Wensch, 2014) or an implicit Rosenbrock-type method. In the present study, ASAM is deployed as a LES model, for which part of the turbulent motion is resolved directly and the remaining part is parameterized by a subgrid-scale model.

As this study focuses on the fundamental understanding of the acting processes in order to test the basic conceptual model of fire-driven dust emissions, the complexity of the study design is kept low. To simulate the impacts of wildfires on the wind patterns, ASAM was set up as follows: the fire itself is assumed to be stationary and represented by a constant flux of sensible heat as a measure for the fire intensity following the assumption of an ideal blackbody. This approach omits the feedback mechanism from the atmosphere acting on the fire development, which, for example, would drive the fire spreading and fuel consumption. The fire heat source was specified as a lower boundary condition of the model as it is typical for grassland and shrubland fires.

The horizontal extent of the model domain was set to $6.4 \times 1.2 \mathrm{~km}^{2}$. This size ensures that the fire-induced atmospheric dynamics can develop undisturbed within the model domain and are not influenced by boundary effects. The longer extent in $x$ direction is aligned with the mean flow direction. The atmospheric flow was initialized in the $x$ direction ( $u$ component of the wind) only, whereas in the $y$ direction only turbulent fluctuations of the wind occur. A schematic plot of the $x-y$ plane of the model domain is given in Fig. 2. The fire area is located $100 \mathrm{~m}$ away from the inflow boundary and centered in the $y$ direction. Using periodic boundary conditions, valuable for the formation of a turbulent PBL, the position of the fire area would be in principle unimportant. The top of the model domain is set to $4000 \mathrm{~m}$ with a damping layer at the upper $200 \mathrm{~m}$, which allows for an undisturbed spreading of the fire-related updraft. The horizontal grid spacing was set to $10 \mathrm{~m}$, the vertical grid spacing was set to $10 \mathrm{~m}$ from ground level to $1000 \mathrm{~m}$ in altitude, to $20 \mathrm{~m}$ for 1000 to $2000 \mathrm{~km}$ in altitude, and to $40 \mathrm{~m}$ for altitudes above $2000 \mathrm{~km}$. Using an explicit Runge-Kutta scheme, the model time step was set to $0.2 \mathrm{~s}$.

To investigate the impacts of the fire on the near-surface winds as realistically as possible, the fire was ignited already in a turbulent PBL as suggested by the model study of Sun et al. (2009), who found that the usage of a time-averaged wind within the PBL does not map the fire properties and the 


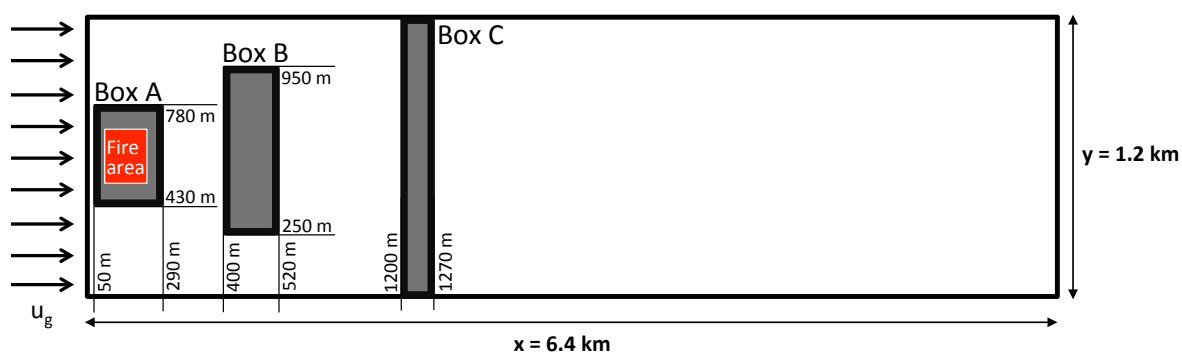

Figure 2. Schematic view of the $x-y$ plane of the model domain. Three areas with different distances from the fire area are marked (boxes A, $\mathrm{B}, \mathrm{C}$ ). Each box has a base size of $84000 \mathrm{~m}^{2}$ (figure not true to scale).

interaction with the atmosphere in such a correct way as a more realistic turbulent PBL does. The formation of such a turbulent PBL requires a spin-up time of the model while the turbulent nature of the PBL can develop. After forcing initial perturbation of the temperature field of $0.2 \mathrm{~K}, 2 \mathrm{~h}$ later it can be guaranteed that a well-mixed and representative PBL with a largely constant depth has developed, so that the fire could be initialized. Due to the periodic boundary conditions, the simulations were stopped at the time when the fireinfluenced atmospheric fields transported downstream by the ambient air flow reach the end of the model domain or at latest $40 \mathrm{~min}$ after fire ignition. Thus, in total each simulation covers $2 \mathrm{~h} 40 \mathrm{~min}$.

Since the occurrence of fires peaks in semiarid regions, a typical Sahelian dry-season atmospheric profile consisting of pressure, temperature, and humidity fields, one of the global fire hot spots, was representatively used. This profile was compiled using model outputs of the mesoscale model COSMO-MUSCAT (Tegen et al., 2013; Wagner et al., 2016) by averaging the wintertime atmospheric fields 2007/2008 of the Sahel region.

In order to further elaborate the impact of the fire on the wind fields at different distances from the fire, three equally sized $\left(84000 \mathrm{~m}^{2}\right)$ areas (boxes A, B, and C) located at different distances from the fire area were defined and illustrated in Fig. 2. Each box has a size of $84000 \mathrm{~m}^{2}$. Box A covers the fire area and its surroundings with an extent of $240 \times 350 \mathrm{~m}^{2}$, box B is shifted slightly downstream to $x=400 \mathrm{~m}$ and has an extent of $120 \times 700 \mathrm{~m}^{2}$, and box $\mathrm{C}$ is located $1000 \mathrm{~m}$ downwind from the fire area at $x=1200 \mathrm{~m}$ and covers an area of $70 \times 1200 \mathrm{~m}^{2}$.

\section{Sensitivity studies of different controlling factors}

To test the conceptual model of dust emissions related to wildfires in general and to investigate the influence of possible controlling factors, sensitivity studies with different input parameters were conducted. The main focus lies on the variation in the fire properties and the ambient wind velocity as probably the most important factors influencing the fire-related wind patterns. Additionally, a non-fire simulation
(NO-FIRE) with an undisturbed non-fire PBL was performed as a reference. An overview of all performed case studies is given in Table 1. If not affected by the chosen setup (see Table 1), the following parameters were kept constant for all other case simulations:

1. roughness length: $z_{0}=0.1 \mathrm{~m}$;

2. ambient mean wind velocity: $\left|u_{g}\right|=3 \mathrm{~m} \mathrm{~s}^{-1}$;

3. fire sensible heat flux: $F_{\text {fire }}=150 \mathrm{~kW} \mathrm{~m}^{-2}$;

4. fire size: $A_{\text {fire }}=70 \times 100 \mathrm{~m}^{2}=7000 \mathrm{~m}^{2}$;

5. fire shape: rectangular.

The roughness length was set to $0.1 \mathrm{~m}$ as a typical mean value for grassland- and shrubland-dominated landscapes, the primarily burning vegetation classes (Roberts et al., 2009; Gatebe et al., 2014). The average wind velocity of $u_{g}=3 \mathrm{~m} \mathrm{~s}^{-1}$ was chosen since this value represents a wellbalanced equivalent to typical atmospheric conditions and within a range often reported as background wind conditions during wildfires (e.g., Coen et al., 2004; Clements et al., 2007; Clark et al., 1999; Frankman et al., 2013; Lareau and Clements, 2017). To cover a broader range and investigate the impacts of different ambient wind velocities on fire-related dust emission potential, weaker $\left(u_{g}\right.$ $=1 \mathrm{~m} \mathrm{~s}^{-1}$, WEAK-WIND simulation) and stronger $\left(u_{g}=\right.$ $5 \mathrm{~m} \mathrm{~s}^{-1}$, STRONG-WIND) ambient wind conditions were also simulated. The ambient wind was forced with a logarithmic wind profile only in the $x$ direction, so that due to the turbulent nature of the simulated PBL, the values of the ambient wind velocity represent the mean wind velocities in the $x$ direction before fire ignition. The average wind speed in the $y$ direction is around zero due to a compensation of positive and negative orthogonal fluctuations.

In order to investigate the influence of different fire properties on the fire-related wind fields as broadly as possible, the fire intensity, size, and shape were modified. One of the main fire characteristics is the fire intensity, expressed by a flux of sensible heat released by the fuel consumption. Values reported in the literature vary quite substantially in orders of 
Table 1. Overview of the case studies.

\begin{tabular}{lrrrll}
\hline Simulation name & $\left|u_{g}\right|\left(\mathrm{m} \mathrm{s}^{-1}\right)$ & $F_{\text {fire }}\left(\mathrm{kW} \mathrm{m}^{-2}\right)$ & $A_{\text {fire }}\left(\mathrm{m}^{2}\right)$ & Fire shape & Description \\
\hline NO-FIRE & 3 & - & - & - & $\begin{array}{l}\text { control run (no fire) } \\
\text { reference case (moderate ambient winds, } \\
\text { REF-CASE }\end{array}$ \\
& 3 & 150 & $7000=70 \times 100$ & rectangular & \\
WEAK-WIND & 1 & 150 & $7000=70 \times 100$ & rectangular & weak ambient wind velocity \\
STRONG-WIND & 5 & 150 & $7000=70 \times 100$ & rectangular & strong ambient wind velocity \\
WEAK-FIRE & 3 & 75 & $7000=70 \times 100$ & rectangular & weaker fire \\
STRONG-FIRE & 3 & 270 & $7000=70 \times 100$ & rectangular & stronger fire \\
SMALL-FIRE & 3 & 150 & $1800=40 \times 60$ & rectangular & smaller fire \\
LARGE-FIRE & 3 & 150 & $11700=90 \times 130$ & rectangular & larger fire \\
ORTHO-FIRE & 3 & 150 & $7000=20 \times 350$ & "line" $(1)$ & line fire orthogonal to flow direction \\
PARA-FIRE & 3 & 150 & $7000=350 \times 20$ & "line" (-) & line fire parallel to flow direction \\
\hline
\end{tabular}

magnitude depending on the fuel type, the atmospheric conditions, and fire behaviors as well as the measuring procedure and are in a range of $8 \mathrm{~kW} \mathrm{~m}^{-2}$ to $3 \mathrm{MW} \mathrm{m}^{-2}$ (Lareau and Clements, 2017), whereby the intensity usually increases from small grassland fires to stronger forest (crown) fires (Frankman et al., 2013). In general, the heat fluxes within one fire can fluctuate strongly, making it difficult to link one fire type with an exact corresponding heat flux. Nevertheless, some representative scenarios can be applied. Since the focus of this study lies on grassland and shrubland fires, heat fluxes of $75 \mathrm{~kW} \mathrm{~m}^{-2}$ (WEAK-FIRE), $150 \mathrm{~kW} \mathrm{~m}^{-2}$ (REF-CASE), and $270 \mathrm{~kW} \mathrm{~m}^{-2}$ (STRONG-FIRE) corresponding to the fire type were chosen. These heat fluxes represent typical values for a weaker grassland fire and moderate and more intense shrubland fires (Frankman et al., 2013; Clements et al., 2007; Lareau and Clements, 2017). The corresponding fire radiative temperatures (assuming a perfect blackbody with an emissivity $\varepsilon=1$ ) are approximately 800,1000 , or $1200^{\circ} \mathrm{C}$, respectively. Since the fire is only represented by a heat flux from the surface, the fire temperatures are not directly reflected in the same order of magnitude in the near-surface air temperature fields.

The fire size does not correspond directly to any physically determined fire properties and can vary by orders of magnitude from case to case. Therefore, the values here are more or less randomly set and will only represent the impacts of differently large fire areas. Originating from the standard fire size of $7000 \mathrm{~m}^{2}$ (REF-CASE), a smaller $\left(40 \times 60=1800 \mathrm{~m}^{2}\right.$, SMALL-FIRE) and a larger $\left(90 \times 130=11700 \mathrm{~m}^{2}\right.$, LARGEFIRE) fire area were simulated.

Additionally, the fire shape was investigated using two line fires of the same size but with a length of $350 \mathrm{~m}$ and a width of only $20 \mathrm{~m}$. Their only difference is the orientation of the fire line with respect to the mean flow direction; one fire is orientated orthogonal (ORTHO-FIRE) and the other one parallel to the mean wind direction (PARA-FIRE). The line fire setups were chosen since prescribed grassland fires are often ignited in a line and such fires will most probably interact in a different way with the atmospheric dynamics. Thus, in to- tal nine different fire setups are investigated (see Table 1 for a summary).

\section{Results - impacts of fires on the wind fields}

In the following section the impacts of the fires on the nearsurface wind patterns and some other atmospheric properties will be analyzed and the importance of different influencing parameters characterized. However, before focusing on the fire impacts, the NO-FIRE simulation as the baseline for the majority of the fire setups will be described. To support this, Fig. 3 shows a vertical cross section of the turbulent kinetic energy (TKE) as well as averaged TKE and temperature profiles. The structure of the simulated atmospheric behavior can be clearly observed. A well-mixed PBL with a mean potential temperature of $302 \mathrm{~K}$ and a depth of $860 \mathrm{~m}$ has been developed. Above this height, the free troposphere with a widely laminar flow indicated by very low TKE values is present.

Now, a representative overview of the fire-influenced wind patterns around the fire center is given for all case simulations $20 \mathrm{~min}$ after fire ignition. Therefore, Fig. 4 presents horizontal cross sections of the $x-y$ plane for the lowest model level $(z=5 \mathrm{~m})$, and vertical cross sections of the $x-z$ plane through the center of the fire $(y=600 \mathrm{~m})$ are presented in Fig. 5. In addition to the wind vectors, the air temperature fields are shown in order to indicate the position of the simulated fire and highlight the fire updraft. Focusing on the horizontal cross sections (Fig. 4), the fire areas are clearly visible as zones of strongly enhanced temperatures, a consequence of the intense flux of sensible heat warming the near-surface air layers. Here, $5 \mathrm{~m}$ above ground level, air temperatures are increased by up to more than $150 \mathrm{~K}$ compared to the ambient conditions. Variations in the size and extent of the fire areas between the different simulation setups become obvious. They are related to differences in the original fire size (SMALL/LARGE-FIRE, Fig. 4f, g) and shape (ORTHO/PARA-FIRE, Fig. 4h, i) but also due to impacts of 
(a)

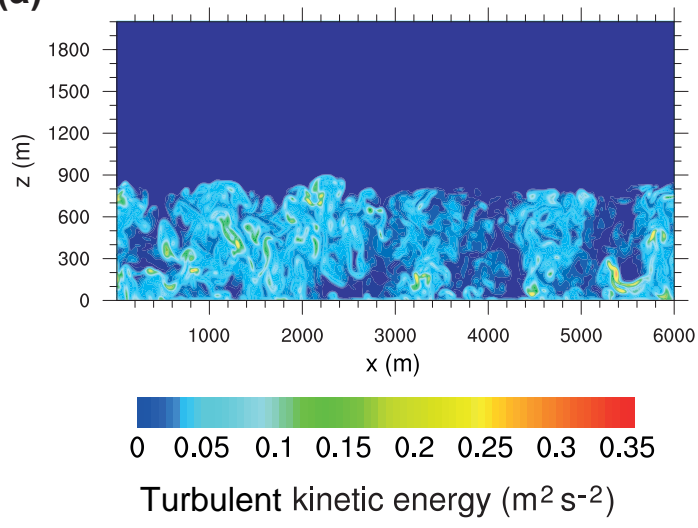

(b)

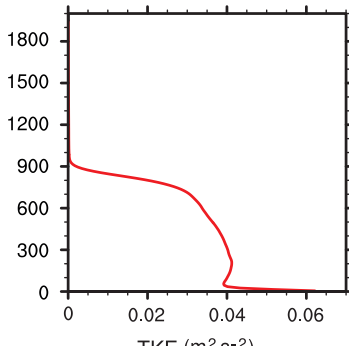

TKE $\left(\mathrm{m}^{2} \mathrm{~s}^{-2}\right)$

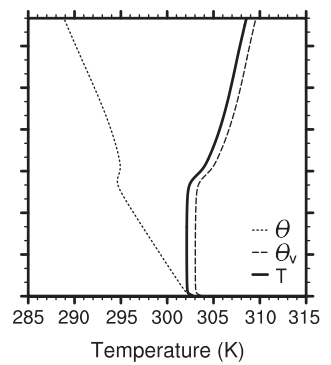

Temperature $(\mathrm{K})$

Figure 3. (a) Vertical cross section of the TKE for the NO-FIRE simulation after $2 \mathrm{~h}$ of spin-up time; (b) averaged vertical profiles of the TKE (left panel), the absolute temperature $T$, potential temperature $\theta$, and virtual potential temperature $\theta_{\mathrm{V}}$ (right panel) for the NO-FIRE simulation.

the ambient wind velocity (REF-CASE, WEAK/STRONGFIRE, Fig. 4a-c). Whereas in the case of calm ambient conditions (WEAK-WIND, Fig. 4b) the original rectangular fire shape remains more or less unchanged within the air temperature fields, a strong deformation with a bulge in flow direction occurs under STRONG-WIND conditions (Fig. 4c) but also in the ORTHO-FIRE setup (Fig. 4h). Regarding both horizontal and vertical wind fields (Figs. 4 and 5), on average a rightward wind (wind flow parallel to the $x$ axis) is present, resulting from the inflow wind velocity forced in the $x$ direction. Additionally, some areas of convergence and divergence and increased and decreased velocities resulting in small vortices are present as is typical for a well-mixed PBL. Zones of strong confluence along with an acceleration of the horizontal winds can be found at and in front of the leading fire edges for the majority of the case simulations (Fig. 4). These areas of confluence develop due to the intense updrafts over the heated fire areas, consistent with the findings of Sun et al. (2009). The corresponding upward motions are clearly visible in the vertical cross sections (Fig. 5), where the initial flows widely parallel to the model's $x$ axis are interrupted by upward-oriented winds embedded within a defined band of increased air temperatures. These areas of strongly increased upward motion are not continuously, and at higher altitudes mostly not located directly, above the fire area. Here, the impact of the ambient wind flow leads to a downstream tilt of the fire updraft, accompanied by downward mixing and a reallocation of the typical non-fire PBL structures. This turbulence generates large vortices, which result in a strong relocation of the atmospheric patterns around the fire updraft. Although Fig. 5 shows only snapshots of the highly turbulent fire-induced wind fields, some differences concerning the orientation and strength of the fire updrafts can be derived. Weak ambient wind velocities (Fig. 5b, WEAKWIND) lead to a defined vertical orientation of the fire up- draft with only small impacts on the remaining atmosphere. In contrast, stronger ambient wind conditions (with the maximum of $5 \mathrm{~m} \mathrm{~s}^{-1}$ in the STRONG-WIND scenario, Fig. 5c) are related to a more downstream tilted flow direction of the heated air and do not reach high altitudes above the fire area. Hence, calm ambient wind conditions lead to an intense upward motion of the heated air; stronger winds impact the lower tropospheric levels downstream of the fire more. Major differences among the remaining simulations (different fire properties, Fig. 5d-i) mainly affect the strength of the winds originating from the fire area. As expected, they are more pronounced during the STRONG-FIRE (Fig. 5e) and LARGE-FIRE (Fig. 5g) cases, which provide a higher energy release, and are comparably weak for the WEAK-FIRE (Fig. 5d) and SMALL-FIRE (Fig. 5f) cases. The line fires, especially the orthogonally orientated one (Fig. 5h, ORTHOFIRE), also generate weaker updrafts.

The strength of the horizontal convergence near the surface is as diverse as the development of the fire updrafts (Fig. 4). Comparable to the updraft strength, the convergence is particularly strong in the STRONG-FIRE (Fig. 4e) and LARGE-FIRE (Fig. 4g) cases. In the presence of higher ambient winds, the convergence zone is shifted further downstream (Fig. 4c, STRONG-WIND), while during calm conditions the convergence takes place right within the fire area and leads partly to a reversal of the flow direction (Fig. 4a, WEAK-WIND) back to the fire area.

The different impacts of the ambient wind velocity on the distribution of the fire-related winds can be expressed more clearly by profiles of the horizontal and vertical peak wind speeds as depicted in Fig. 6. Here, vertical profiles are shown for the areas (boxes A-C) with respect to the distance from the fire as described in Sect. 2 and shown in Fig. 2. Although only maximum values are given, these values still represent an average of the peak wind velocities before and after fire 


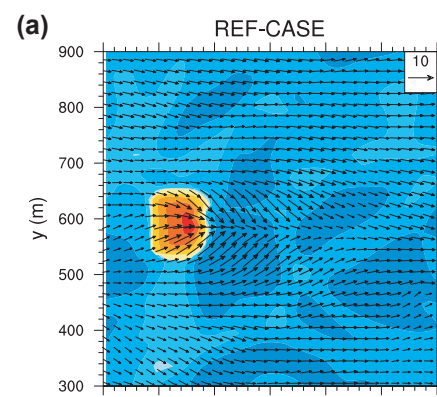

(b) WEAK-WIND
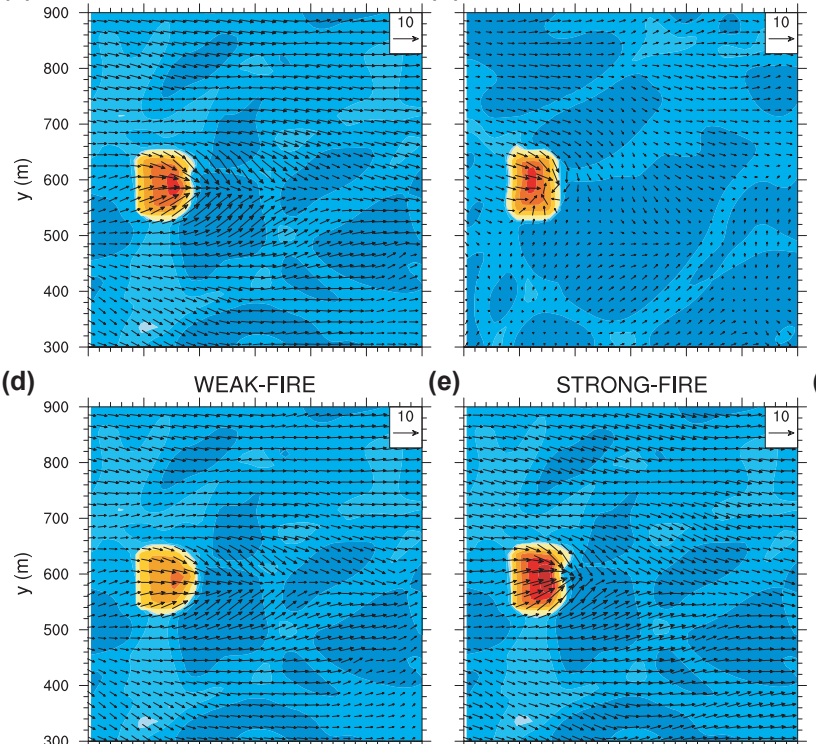

(e) STRONG-FIRE

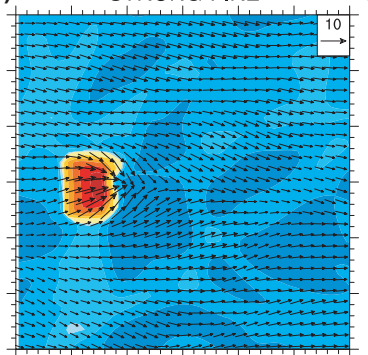

(h)

(g)

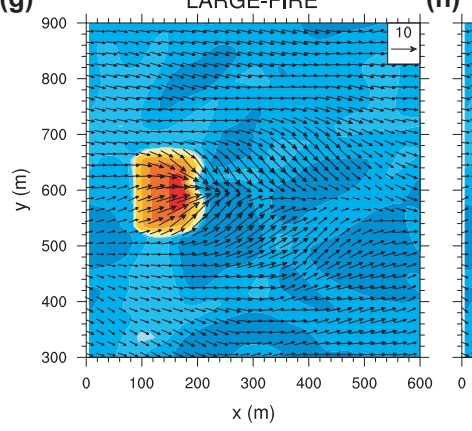

ORTHO-FIRE

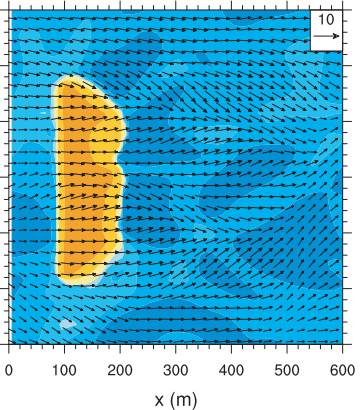

(c) STRONG-WIND

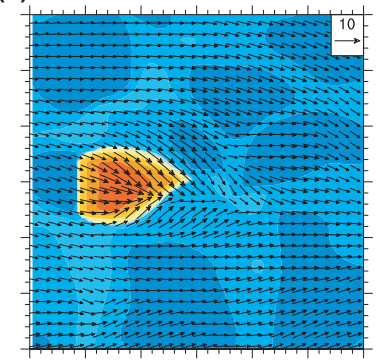

(f)

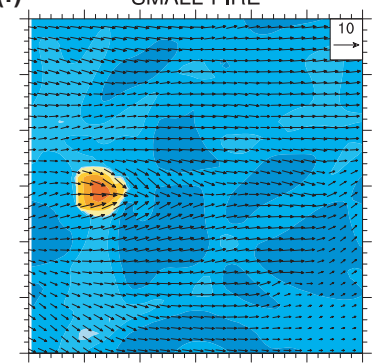

(i)
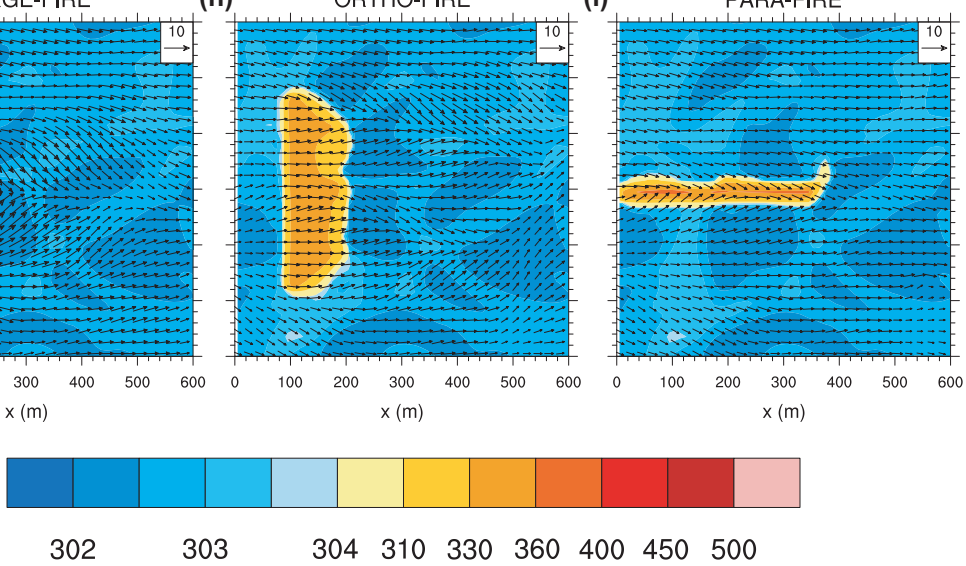

Air temperature (K)

Figure 4. Horizontal cross sections of the wind vector and air temperature fields $20 \mathrm{~min}$ after fire ignition in the lowest model level of $z=5 \mathrm{~m}$.

ignition. This approach allows a better representation of the fire-related winds without a vanishing of the peak values due to a merging with the uninfluenced wind field around the fire updraft or corresponding downdrafts. Compared are the profiles of the undisturbed non-fire PBL (dashed lines) with the profiles after fire ignition (solid lines) for the scenarios with a different ambient wind velocity (WEAK-WIND, REF-CASE, STRONG-WIND) varying from 1 to $5 \mathrm{~m} \mathrm{~s}^{-1}$.

The undisturbed non-fire wind profiles are well separated by the different ambient wind velocities and show quite clearly the modeled PBL height of roughly $900 \mathrm{~m}$. Above this altitude, the horizontal wind peaks are close to the average ambient wind velocity and the vertical wind velocity is close to zero, representing together a widely undisturbed, laminar flow. Below, turbulent fluctuations result in peak wind val- ues of on average up to $2 \mathrm{~m} \mathrm{~s}^{-1}$ above the mean flow velocity. The fire impacts change the situation drastically. Now much higher peak values can be observed, whereby with increasing distance from the fire area a weakening of the peak winds near the surface and a continuous lifting of the most impacted air layers occur. During WEAK-WIND conditions, the fire energy is mainly transformed into an upward motion, which results in a strong modification of the atmospheric patterns up to a height of some kilometers. Due to the strong turbulence occurring around the fire updraft, the horizontal winds become enhanced too. In contrast, in the presence of higher ambient wind forces such as $3 \mathrm{~m} \mathrm{~s}^{-1}$ (REF-CASE) or $5 \mathrm{~m} \mathrm{~s}^{-1}$ (STRONG-WIND), the updraft is much weaker but modulations in the near-surface horizontal winds are more pronounced. Thus, the atmospheric patterns are vertically 

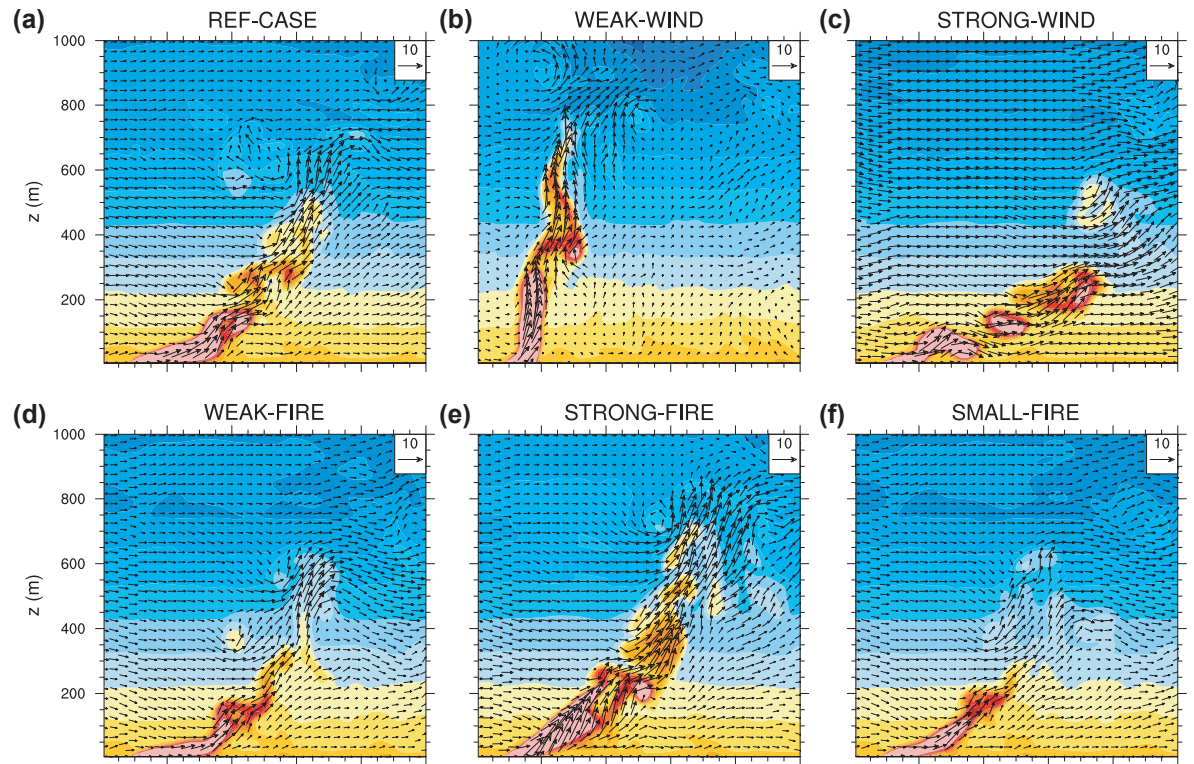

(e)

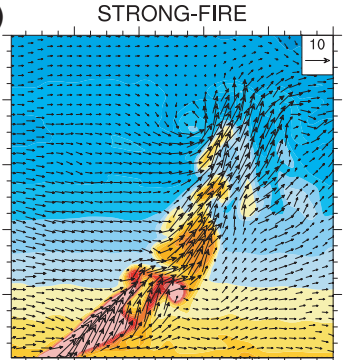

(f)
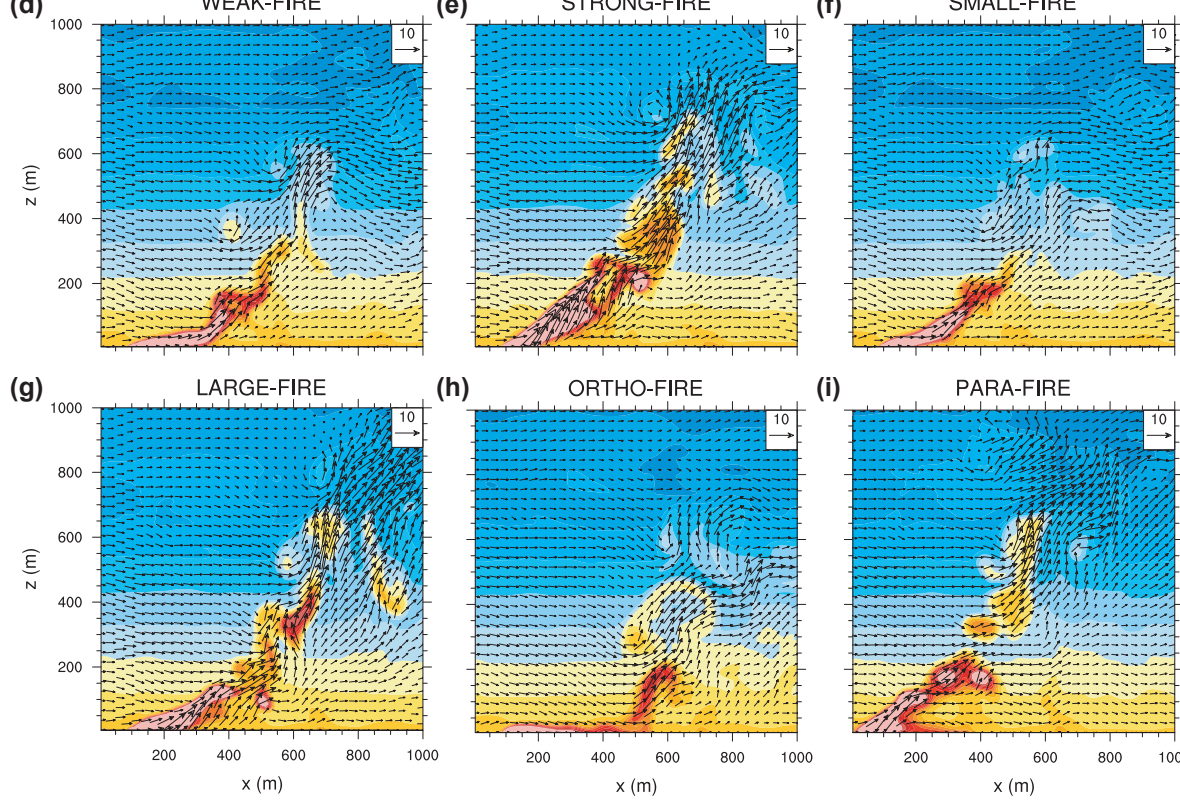

(h)
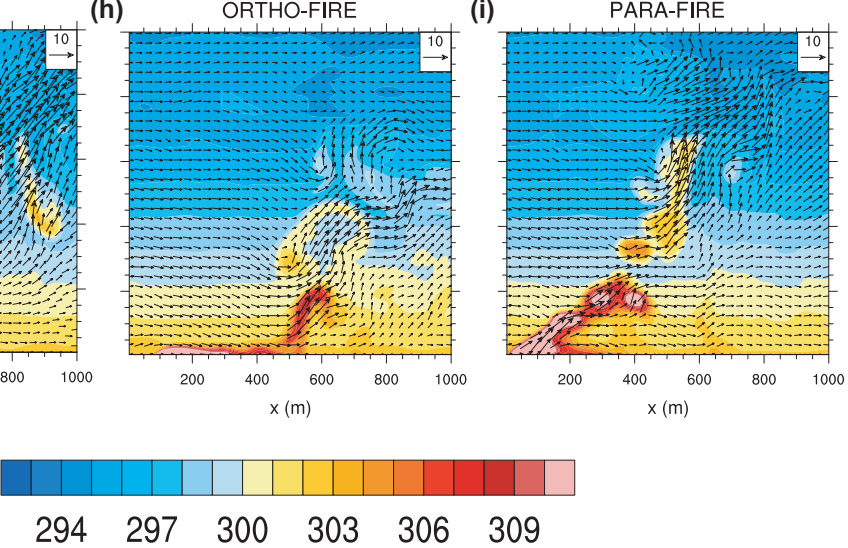

Air temperature $(\mathrm{K})$

Figure 5. Vertical cross sections of the wind vector and air temperature fields through the fire center $(y=600 \mathrm{~m}) 20 \mathrm{~min}$ after fire ignition.

less impacted but the faster downstream transport of the firegenerated turbulence impacts a much larger area in the flow direction. The fire properties modulate the scenario in an expected way such that LARGE-FIRE and STRONG-FIRE, but also ORTHO-FIRE, lead generally to higher peak wind velocities and impact higher tropospheric levels. But they are, concerning the general behavior, widely comparable with the REF-CASE scenario, suggesting that the ambient wind velocity is the main driver of the different atmospheric distribution of fire-induced turbulence.

The increased atmospheric turbulence triggered by the fire updraft can also be expressed by the TKE. Therefore, Fig. 7 shows the vertical profiles of fire-generated peak TKE values computed similarly to the wind profiles shown in Fig. 6. All setups have the commonality that the fire-induced turbulence generates peak TKE values of $3-12 \mathrm{~m}^{2} \mathrm{~s}^{-2}$, which is more than an order of magnitude higher than the NO-FIRE peak values of $0.4 \mathrm{~m}^{2} \mathrm{~s}^{-2}$. Additionally, each setup shows enhanced values above the modeled PBL, suggesting a turbulent mixing also above the PBL. However, a strong decline with increasing height is often present and the highest values occur within the lowest 100-200 m directly above and around the fire area. The only exception is again the WEAKWIND simulation (Fig. 7a) in which the strong updraft induces the strongest turbulence at higher altitudes. As expected, the stronger and larger a fire, the higher the peak TKE values and the deeper the fire-induced turbulence penetrates into the atmosphere. The line fires (ORTHO/PARA-FIRE) are related to a weaker turbulence compared to the rectangular fire of the same size and intensity (REF-CASE) since the fire energy release to the atmosphere is more distributed over a larger area and is less concentrated, which results in 


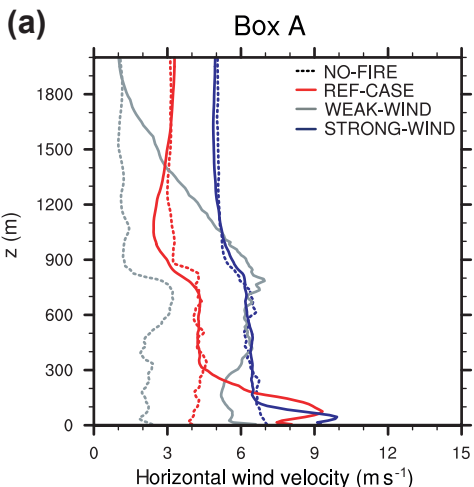

(d)

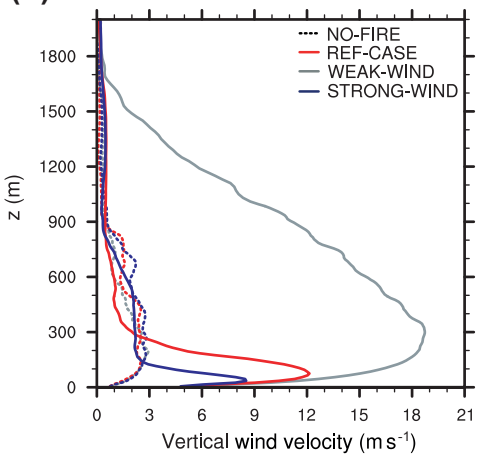

(b)

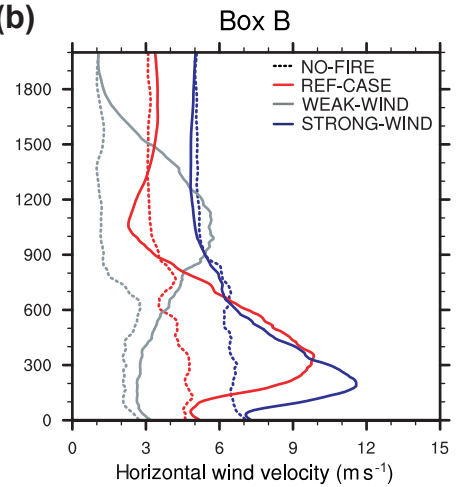

(e)

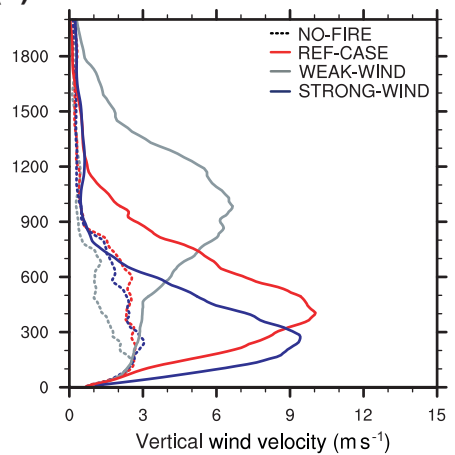

(c)

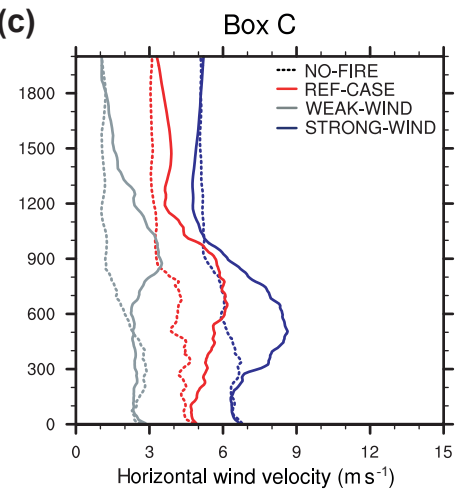

(f)

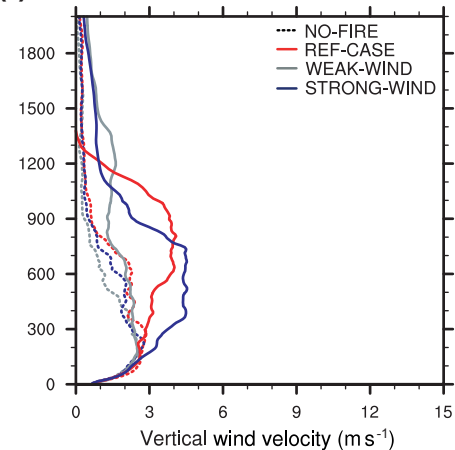

Figure 6. Vertical profiles of the horizontal (upper row) and vertical (lower row) wind velocity for the simulations with a different ambient wind velocity (WEAK-WIND, REF-CASE, and STRONG-WIND) and different distances from the fire (boxes A, B, C in Fig. 2). Shown are the atmospheric profiles after fire ignition (solid line) with the profile in the undisturbed non-fire situations (dashed line). Plotted are means of the maximum values per time step.

less strong peak TKE values. However, this feature impacts only the lowest tropospheric levels and is not present above (Fig. 7d).

Since the focus of this study lies predominantly on the potential of wildfires to mobilize soil dust particles and the emission of mineral dust is primarily a threshold problem, the crucial point is the occurrence of high wind speeds at the surface. To investigate the frequency of occurrence and the strength of such strong winds or gusts, probability density functions (PDFs) of the horizontal wind velocity $5 \mathrm{~m}$ above ground are calculated. In order to analyze the impacts of the fire, the fire-affected wind PDFs are compared to the PDFs of the undisturbed non-fire winds. The non-fire wind PDFs are calculated from the last $5 \mathrm{~min}$ before fire ignition when the PBL is fully developed. Accordingly, the calculation of the PDFs, representing the fire-induced wind fields directly within the fire area and with respect to different distances from the fire (boxes $\mathrm{A}-\mathrm{C}$ ), uses all time steps immediately after fire ignition (fire area, box A) or even later after it can be guaranteed that the downstream-transported fire-induced wind patterns reach the area of interest, which means $10 \mathrm{~min}$ after fire ignition for box $\mathrm{B}$ and a further $10 \mathrm{~min}$ later for box C. In Fig. 8, PDFs of the horizontal near-surface wind velocity within the direct fire area are shown for all case sim- ulations. Additionally, fractions of wind velocities exceeding a non-fire limit of usually $6 \mathrm{~m} \mathrm{~s}^{-1}$ (except for the WEAKWIND and STRONG-WIND simulations with 4 or $8 \mathrm{~m} \mathrm{~s}^{-1}$, respectively) are also given in Table 2 for the other distances from the fire area (boxes A-C; see Fig. 2).

The non-fire wind speed distribution as illustrated by dashed lines in Fig. 8 follows a Gaussian distribution with the most frequently occurring wind velocities within an order of magnitude of the initial ambient wind velocity (1 and $5 \mathrm{~m} \mathrm{~s}^{-1}$ for, respectively, the WEAK-WIND and STRONGWIND setups; $3 \mathrm{~m} \mathrm{~s}^{-1}$ for all other cases). These wind velocities fluctuate up to $3 \mathrm{~m} \mathrm{~s}^{-1}$ around the average due to the turbulent nature of the simulated PBL. During the presence of a fire, the whole distributions are shifted significantly towards higher values with a huge frequency of high wind velocities, which were not present before fire ignition in the non-fire PBL.

Figure 8 a contrasts the wind PDFs for the fire scenarios under different ambient wind velocities. It stands out that the differences of the mean wind velocity among the individual scenarios of $2 \mathrm{~ms}^{-1}$ each lead to a nearly perfect shift of the undisturbed non-fire wind PDFs towards $2 \mathrm{~m} \mathrm{~s}^{-1}$ higher wind velocities. However, the fire PDFs behave differently. Although the PDF for the STRONG-WIND 
(a)

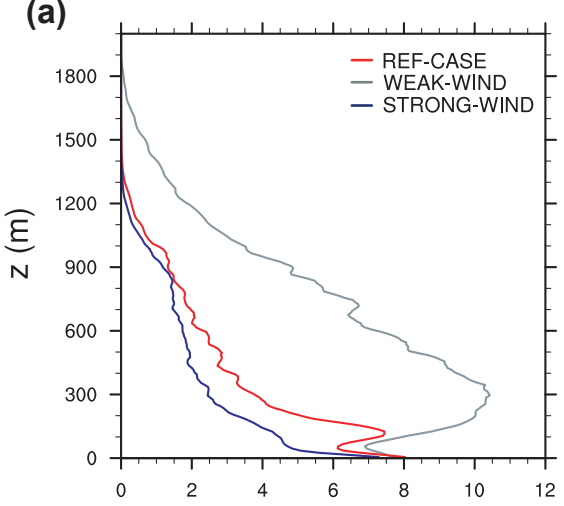

(c)

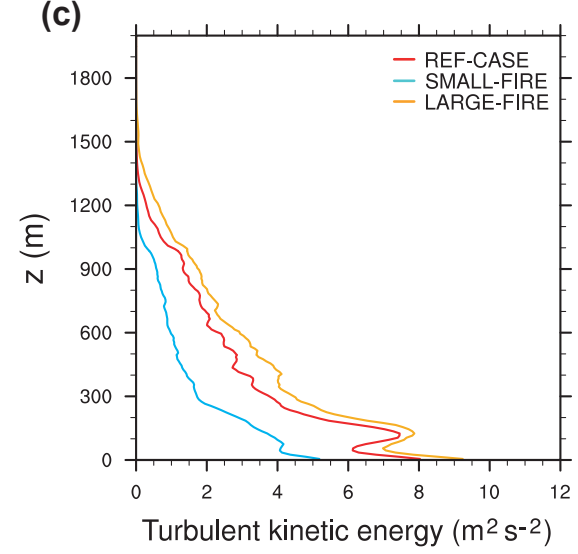

(b)

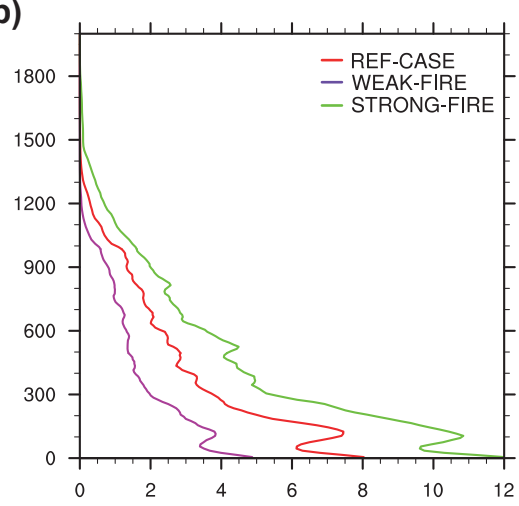

(d)

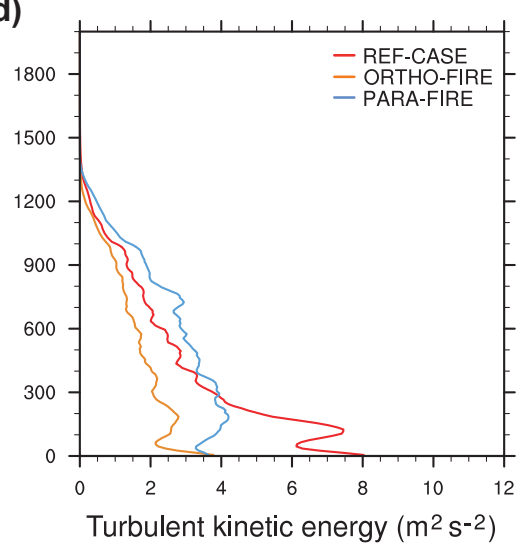

Figure 7. Vertical profiles of the turbulent kinetic energy (TKE) for the different case simulations. Compared are the impacts of (a) different ambient wind velocities, (b) fire intensities, (c) fire sizes, and (d) fire shapes and orientations. Plotted are means of the maximum values per time step.

setup is still the one that is related to the highest wind velocities, the differences among all three scenarios become smaller. The WEAK-WIND distribution is shifted by $4 \mathrm{~m} \mathrm{~s}^{-1}$ to higher wind velocities, whereas the STRONG-WIND distribution is only shifted by $2 \mathrm{~m} \mathrm{~s}^{-1}$, which leads to a reduction among the single PDFs of originally 4 to only $2 \mathrm{~m} \mathrm{~s}^{-1}$. This indicates that the fire impact on the fire-induced nearsurface winds is much stronger compared to the influence of the mean ambient wind velocity. In the case of the WEAKWIND simulation this becomes particularly obvious where the fire-influenced and non-fire PDFs show nearly no overlap ( $86 \%$ of the wind velocities exceed the non-fire threshold). However, a higher ambient wind velocity increases the likelihood to reach certain (threshold) wind velocities at similar fire properties, although the maximum velocities are comparable (see Table 3), but the frequency of occurrence differs.

The impacts of different fire intensities on the wind speed distribution in the fire area are given by Fig. 8b. Again, a distinct shift of all the PDFs towards higher wind velocities occurs in all cases. However, this is most dominant for the more intense fires. In our setup, the STRONG-FIRE leads to maximum wind velocities within the fire area of up to $11 \mathrm{~m} \mathrm{~s}^{-1}$, whereas WEAK-FIRE accelerates the near-surface winds up to only $8 \mathrm{~m} \mathrm{~s}^{-1}$. An additional feature, which can be derived from Fig. $8 \mathrm{~b}$ is that with increasing fire intensity, the distribution becomes wider. This means that the increase in the occurrence of the highest wind speeds does not lead to a reduction of the lowest wind velocities in the same order of magnitude. But to conclude the sub-figure, the more intense the fire, the more frequently wind velocities above the nonfire limit occur and the stronger they are.

The dependency of the fire PDFs on the fire size is shown in Fig. 8c for the rectangular fires with a size of 1800 (SMALL-FIRE), 7000 (REF-CASE), and $11700 \mathrm{~m}^{2}$ (LARGE-FIRE). In general, the following connection is obvious: the larger the fire, the stronger the shift in the wind speed distribution within the fire area towards higher values. Comparable to the impact of the fire intensity, an increase in the fire size is also related to a broadening of the fire PDFs, which means that the occurring wind velocities in a larger fire area cover a wider range compared to smaller ones. The highest wind velocities, however, appear to be not as strongly impacted by the fire size as by the fire intensity. 
(a)

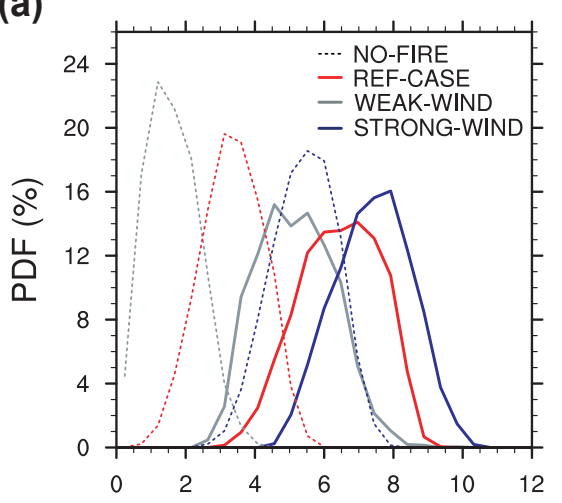

(c)

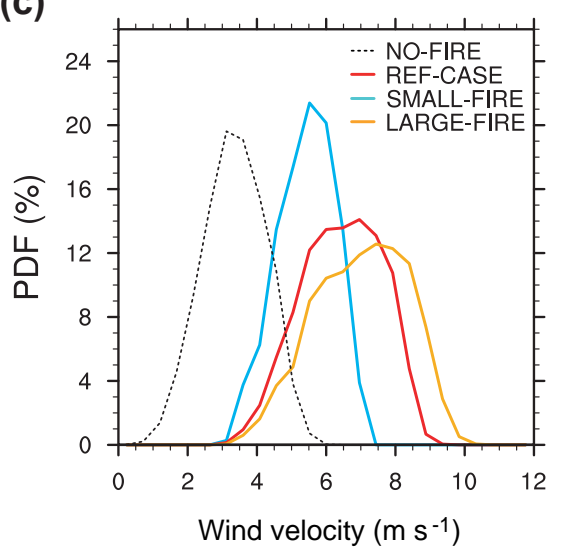

(b)

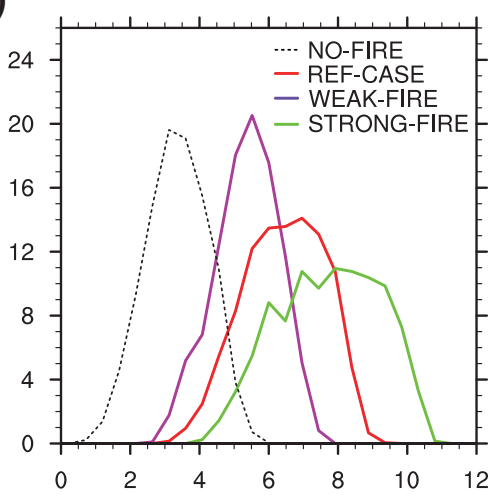

(d)

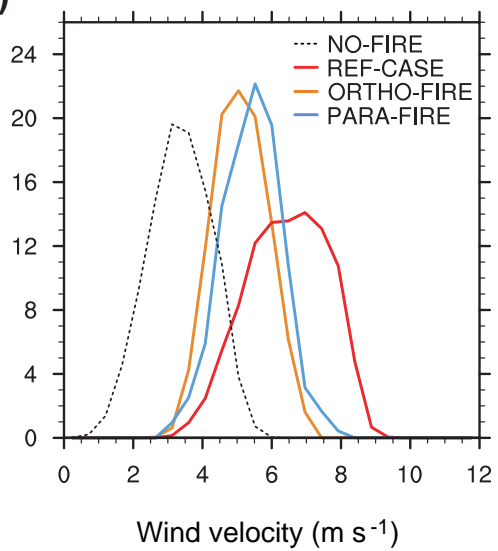

Figure 8. PDFs of the near-surface wind velocity within the fire area for the different case simulations (solid lines) with respect to the PDFs of the non-fire situations (dashed lines). Shown are the impacts of different (a) ambient wind velocities, (b) fire intensities, (c) fire sizes, and (d) fire shapes and orientation - always with respect to the REF-CASE simulation.

Table 2. Fraction of the wind velocities larger than the non-fire limit for the direct fire area and the three boxes $\mathrm{A}, \mathrm{B}$, and $\mathrm{C}$ with different distances from the fire area (see Fig. 2). For the majority of the simulations with an ambient wind velocity of $3 \mathrm{~m} \mathrm{~s}^{-1}$, this upper non-fire threshold lies at $6 \mathrm{~m} \mathrm{~s}^{-1}$ (frequency of occurrence $>99.99 \%$ ). For the WEAK-WIND and STRONG-WIND simulations, different threshold values of 4 and $8 \mathrm{~m} \mathrm{~s}^{-1}$ are used. Additionally, the fractions concerning the $6 \mathrm{~m} \mathrm{~s}^{-1}$ limit are indicated in brackets here, too.

\begin{tabular}{lrrrr}
\hline Simulation & Fire area & Box A & Box B & Box C \\
& $\%$ & $\%$ & $\%$ & $\%$ \\
\hline NO-FIRE & 0.05 & 0.03 & 0 & 0 \\
REF-CASE & 63.3 & 13.3 & 1.1 & 0.3 \\
WEAK-WIND & $85.8(27.3)$ & $9.8(2.6)$ & $0.1(0)$ & $0(0)$ \\
STRONG-WIND & $31.0(88.4)$ & $11.8(56.0)$ & $0.8(42.4)$ & $0(28.3)$ \\
WEAK-FIRE & 24.7 & 6.6 & 0.4 & 1.1 \\
STRONG-FIRE & 85.0 & 21.0 & 2.3 & 1.9 \\
SMALL-FIRE & 25.0 & 3.2 & 0.05 & 1.5 \\
LARGE-FIRE & 74.4 & 25.7 & 4.0 & 1.6 \\
ORTHO-FIRE & 10.8 & 18.3 & 5.4 & 1.2 \\
PARA-FIRE & 25.8 & 4.6 & 0.5 & 0 \\
\hline
\end{tabular}

Finally, the fire shape also impacts the strength and frequency of occurrence of wind speeds above the non-fire limit (Fig. 8d). Comparing line fires orthogonal (ORTHO-FIRE) and parallel (PARA-FIRE) to the flow direction with a rect- angular fire of the same size and intensity (REF-CASE), differences in the shape of the fire-influenced wind PDFs stand out. Both line fire PDFs behave quite similarly with only small differences. They are both shifted by roughly $2 \mathrm{~m} \mathrm{~s}^{-1}$ 
towards higher wind velocities; however, the highest values are much weaker compared to the rectangular fire, where the fire area and thus the heat source modulating the wind patterns are more concentrated, which supports the creation of higher wind velocities.

Since the fire-related updrafts often first develop downstream of the direct fire area (see Figs. 4-5), the area surrounding the fire might be of interest too with regard to the occurrence of high winds. Therefore, the fraction of the exceedances of wind velocities above the non-fire limits is given for box A (covering the fire area plus the surrounding area as shown in Fig. 2) in Table 2 compared to that of the direct fire area. As expected, for the majority of cases the occurrence of wind velocities above the non-fire limit decreases significantly as now also regions that are not influenced by the fire are included in the PDF calculation. However, especially in the case of STRONG-FIRE and LARGE-FIRE, a remarkable fraction of wind velocities still exceed the nonfire limit. The behavior of the perpendicular-orientated line fire (ORTHO-FIRE) stands out. In this case, a significant increase in wind velocities greater than $6 \mathrm{~m} \mathrm{~s}^{-1}$ occurs. The long orthogonal extent of the fire line leads to a much broader area of fire-induced turbulence downstream of the fire line. Although the total impacts concerning the maximum wind values are smaller compared to the rectangular fire setup, the long fire line precludes/impedes a mixing of the fire-induced atmospheric pattern with uninfluenced non-fire flow effectively for a long distance, which means that the fire-induced patterns are present much longer in the flow direction before a weakening of the impacts takes place. Thus, the creation of higher wind velocities is much more strongly impacted downstream of the fire area than in the small fire area itself.

With an increasing distance from the fire area the impacts of the fire on the near-surface wind fields weaken drastically but are often still present due to a further downstream transport of fire-related turbulence and momentum, which also favors the occurrence of higher wind velocities at some distances from the fire. Already some hundreds of meters downstream of the fire area, in box B, the shift of the wind PDFs and occurrence of above-average wind velocities is mostly very small or nearly insignificant in the case of WEAK-WIND conditions and at SMALL-FIRE sizes. Only STRONG-FIRE, LARGE-FIRE, and again ORTHOFIRE also show noteworthy impacts further ahead of the fire area because these fire setups are related to a stronger generation of turbulence, which is transported downstream and can affect the wind field there much more effectively than the weaker turbulence of smaller and weaker fires. In the case of ORTHO-FIRE, the effect is again most pronounced and even the highest wind velocities near the surface can be found first within box B and thereby some hundreds of meters away from the actual fire area. Surprisingly, the fraction of wind velocities above the non-fire limit is with 1-2\% still enhanced in box $\mathrm{C}$, more than $1 \mathrm{~km}$ away from the fire area for most of the fire setups. This feature will be analyzed in more detail in the following section, in which maps of spatial distributions are shown.

\section{Discussion with regard to dust emission potential}

The analysis of the near-surface wind patterns has already illustrated that wildfires lead, depending on the state of the atmosphere and the fire properties, to a significant increase in the strength and frequency of occurrence of peak wind velocities. Since especially these high wind speeds are important for dust emission, the substantial increase in the frequency of occurrence of wind velocities larger than $6 \mathrm{~m} \mathrm{~s}^{-1}$ indicates a strongly increased dust emission potential during wildfires. To test the conceptual model of fire-related dust emissions, a simplified approach was used. For the dust mobilization itself, a representative horizontal threshold velocity of $6 \mathrm{~m} \mathrm{~s}^{-1}$ was applied, although in reality the exact value depends on several surface characteristics. However, this value is commonly used and can be linked to a high likelihood of a dust emission event. The spatial distribution of areas where and how often this threshold of $6 \mathrm{~m} \mathrm{~s}^{-1}$ is exceeded is given in Fig. 9 for all cases, including the NO-FIRE simulation. Additionally, the frequency of exceedance of this threshold velocity summed up over the leftmost $2 \mathrm{~km}$ of the model domain as shown in Fig. 9 is given in Table 3 (first column).

Considering the NO-FIRE simulation (Fig. 9a), it becomes evident that the turbulent fluctuations around the mean ambient wind velocity of $3 \mathrm{~ms}^{-1}$ already lead to an exceedance of the chosen threshold velocity in rare cases. However, these areas are small and randomly distributed over the model domain and at best only once affected by such an exceedance, which means that a significant contribution to dust emission cannot be expected, independent of the predominant surface conditions. All other simulations show a highly increased occurrence of horizontal wind velocities above the threshold within and around the fire area up to $100 \%$, whereas the number and spatial extent depend on the chosen setup. The spatial extent of wind velocities above the threshold of $6 \mathrm{~m} \mathrm{~s}^{-1}$ is greatest during the STRONG-FIRE (Fig. 9f), LARGE-FIRE (Fig. 9h), ORTHOFIRE (Fig. 9i), and STRONG-WIND (Fig. 9d) setups. Concerning the STRONG-WIND simulation with an average wind velocity of $5 \mathrm{~m} \mathrm{~s}^{-1}$, the chosen threshold velocity of $6 \mathrm{~m} \mathrm{~s}^{-1}$ is already regularly exceeded nearly all over the model domain by the normal non-fire turbulent fluctuations. However, here the frequency of occurrence of such horizontal peak winds is also drastically strengthened in the fire surroundings and further downstream. Although the non-fire winds would already be able to generate dust emissions in general, the likelihood and the strength of possible dust emissions is strongly enhanced here as well, especially with regard to fire-related vegetation removal and modification of the soil conditions within the fire area. In particular the cases with an increasing fire size, intensity, and ambient wind ve- 
Table 3. Relative fraction of the exceedance of a horizontal wind velocity $\left(v_{\text {tres }}\right)$ of $6 \mathrm{~m} \mathrm{~s}^{-1}$ and relative fraction of a simultaneous exceedance of different vertical velocities of $w_{1}>0.00014 \mathrm{~m} \mathrm{~s}^{-1}, w_{2}>0.009 \mathrm{~m} \mathrm{~s}^{-1}, w_{3}>0.08 \mathrm{~m} \mathrm{~s}^{-1}, w_{4}>0.27 \mathrm{~m} \mathrm{~s}^{-1}$, and $w_{5}>5.1 \mathrm{~m} \mathrm{~s}^{-1}$, each within the lowest model level at $z=5 \mathrm{~m}$. The values concern the model domain of $2 \times 1.2 \mathrm{~km}^{2}$ shown in Figs. 9-11. Additionally, the peak values of the horizontal near-surface wind velocity $\left(v_{\max , \text { sff }}\right)$ and the total updraft velocity $\left(w_{\max }\right)$ are provided.

\begin{tabular}{lrrrrrrrr}
\hline Simulation & $\begin{array}{r}f\left(v_{\text {tres }}\right) \\
\%\end{array}$ & $\begin{array}{r}\left|v_{\max , \text { srf }}\right| \\
\left(\mathrm{m} \mathrm{s}^{-1}\right)\end{array}$ & $\begin{array}{r}f\left(w_{1}\right) \\
\%\end{array}$ & $\begin{array}{r}f\left(w_{2}\right) \\
\%\end{array}$ & $\begin{array}{r}f\left(w_{3}\right) \\
\%\end{array}$ & $\begin{array}{r}f\left(w_{4}\right) \\
\%\end{array}$ & $\begin{array}{r}f\left(w_{5}\right) \\
\%\end{array}$ & $\begin{array}{r}\left|w_{\max }\right| \\
\left(\mathrm{m} \mathrm{s}^{-1}\right)\end{array}$ \\
\hline NO-FIRE & 0.008 & 6.7 & 0.007 & 0.007 & 0.006 & 0.004 & 0 & 5.4 \\
REF-CASE & 0.9 & 9.3 & 0.4 & 0.4 & 0.4 & 0.3 & 0.006 & 23.3 \\
WEAK-WIND & 0.09 & 9.9 & 0.09 & 0.09 & 0.08 & 0.08 & 0.02 & 26.6 \\
STRONG-WIND & 30.8 & 10.6 & 12.9 & 12.4 & 9.1 & 4.0 & 0.003 & 17.0 \\
WEAK-FIRE & 0.6 & 7.8 & 0.3 & 0.3 & 0.2 & 0.2 & 0 & 16.3 \\
STRONG-FIRE & 1.6 & 10.9 & 0.7 & 0.7 & 0.6 & 0.4 & 0.02 & 28.5 \\
SMALL-FIRE & 0.3 & 7.7 & 0.2 & 0.2 & 0.1 & 0.09 & 0.006 & 14.4 \\
LARGE-FIRE & 2.2 & 10.5 & 0.9 & 0.9 & 0.7 & 0.5 & 0.009 & 25.7 \\
ORTHO-FIRE & 1.8 & 8.7 & 0.9 & 0.9 & 0.7 & 0.4 & 0 & 14.4 \\
PARA-FIRE & 0.3 & 8.0 & 0.2 & 0.2 & 0.1 & 0.09 & 0.0001 & 17.3 \\
\hline
\end{tabular}

locity usually show a fraction of more than $90 \%$ exceedance of the threshold velocity within the direct fire area. Since the fire here usually consumes the vegetation cover, a mobilization of soil dust particles would be expected to take place quite efficiently.

In addition to the general exceedance of the threshold velocity in the fire surroundings, an interesting behavior occurs for simulations with an averaged ambient wind velocity of $3 \mathrm{~m} \mathrm{~s}^{-1}$ and a rectangular fire shape. While during WEAKWIND conditions (Fig. 9b) the potential of the fire to generate wind velocities above the threshold is limited to the direct fire area, such favorable zones have also evolved in the other setups some distance from the fire. Patterns of enhanced wind velocities, similar to a vortex trail behind an island, have developed downstream of the fire area (see Fig. 9b, e-h). The evolution of this pattern might be caused by the strong fire updraft acting as an obstacle within the ambient flow, which has to be circum-flowed by the winds. The resulting strong turbulence at the edges of the fire updraft now propagates downstream, can be mixed downward, and finally leads to enhanced surface winds together with an exceedance of the threshold some distance from the fire area. Provided that suitable surface conditions exist there, the dust emission potential would be increased there as well. Whereas in these cases right in front of the fire area, in the lee of the fire updraft, no above-average wind velocities occur, the situation is quite different in the case of ORTHO-FIRE (Fig. 9i). Although the fraction of exceedances of the threshold velocity is comparably low (only 30-40\%), a large area is affected by such events right downstream of the fire area. Since all other parameters are kept constant, the orientation of the fire to the ambient wind flow direction appears to play an important role by increasing the effective surface prone to wind erosion. ORTHO-FIRE heats the lower atmospheric levels on a wide front along with modulations of the wind patterns there so that a mixing with undisturbed non-fire-influenced air masses first occurs much further downstream in this case. Thus, the fire-induced turbulence can be transported much more efficiently in the flow direction and impacts a much larger area compared to the other setups. This area could be prone to dust emission as well - suitable surface conditions assumed. This special behavior is remarkable insofar as especially here a dust mobilization potential arises, which is not only directly linked to the fire plume but emissions can also take place independently and a mixture with combustion aerosol would not always be satisfied.

An efficient injection of mineral dust particles into higher atmospheric levels also requires, in addition to an exceedance of the horizontal threshold velocity, a strong enough vertical wind velocity. Necessary updraft velocities to lift dust particles in the air are based significantly on particle size and mass. For simplification, sedimentation velocities of representative particle sizes are used to estimate the needed updraft velocities, which must be greater than the sedimentation velocity resulting from gravitational forces to inject and hold the particles in the air. The following particle diameters were chosen for the calculation exemplarily, namely $d_{1}=1.46 \mu \mathrm{m}$ (clay), $d_{2}=12.2 \mu \mathrm{m}$ (small silt), $d_{3}=36 \mu \mathrm{m}$ (large silt), $d_{4}=76 \mu \mathrm{m}$ (small sand) (Tegen and Fung, 1994), and $d_{5}=1000 \mu \mathrm{m}$ (giant particles, large sand). The corresponding sedimentation velocities $v_{\text {sed }}$ of these particle diameters $d_{1}-d_{5}$ result, using the calculations with slip and shape correction based on Hinds $(1982)$, in $v_{\text {sed }}\left(d_{1}\right)=0.00014 \mathrm{~m} \mathrm{~s}^{-1}, v_{\text {sed }}\left(d_{2}\right)=$ $0.009 \mathrm{~m} \mathrm{~s}^{-1}, v_{\text {sed }}\left(d_{3}\right)=0.08 \mathrm{~m} \mathrm{~s}^{-1}, v_{\text {sed }}\left(d_{4}\right)=0.27 \mathrm{~m} \mathrm{~s}^{-1}$, and $v_{\text {sed }}\left(d_{5}\right)=5.06 \mathrm{~m} \mathrm{~s}^{-1}$. This means, to hold and raise particles of such a size in the atmosphere, these velocities have to be exceeded by a fire or an atmospheric updraft. Consequently, they are used here as a simplified assessment of necessary updraft velocities $w_{1}-w_{5}$, which should occur together with an exceedance of the horizontal threshold velocity $v_{\text {tres }}$ for dust particles being effectively emitted into 
(a)

(c)

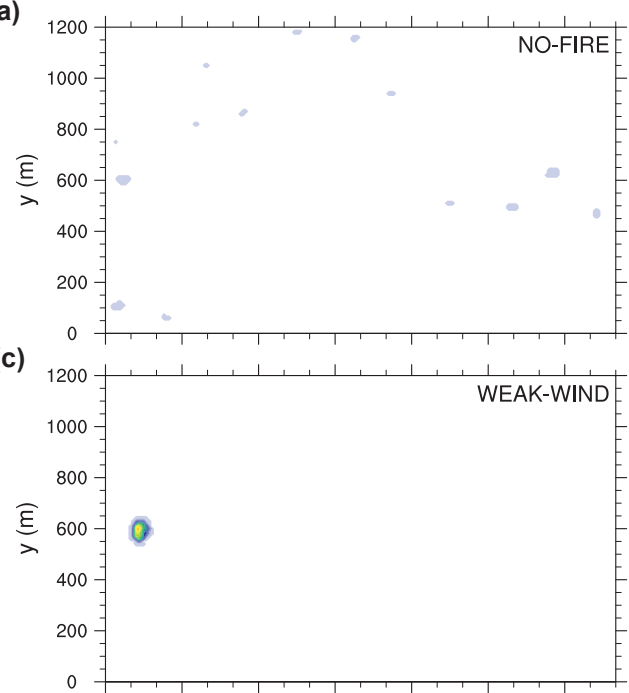

(e)

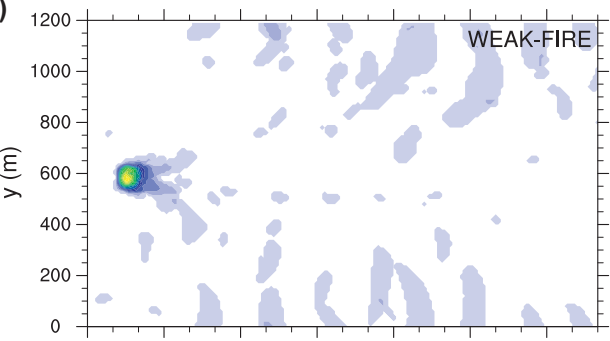

(g)

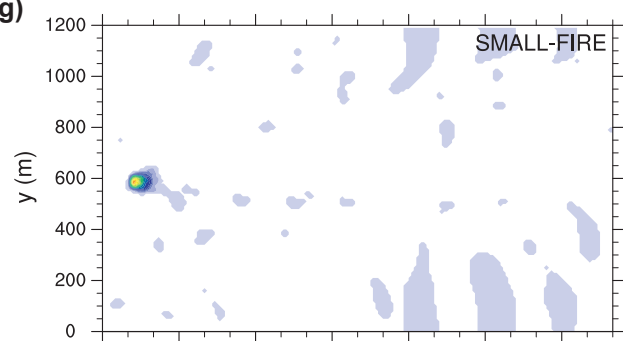

(i)

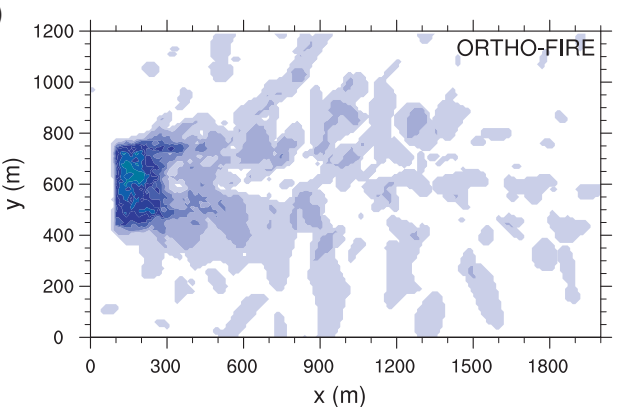

(b)

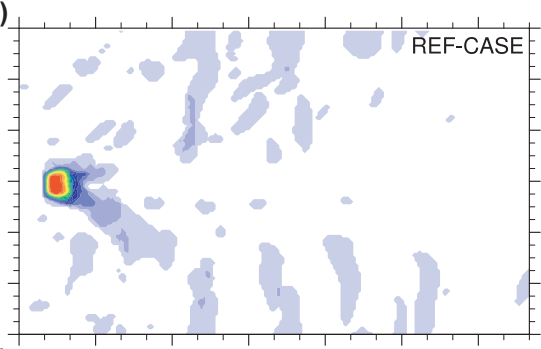

(d)

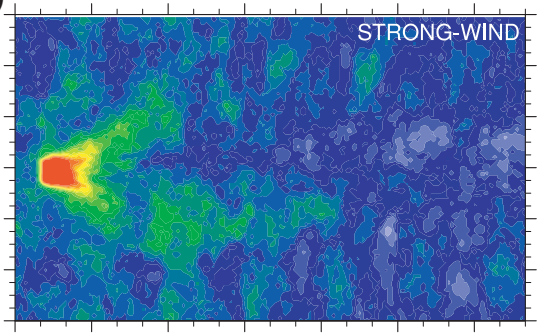

(f)

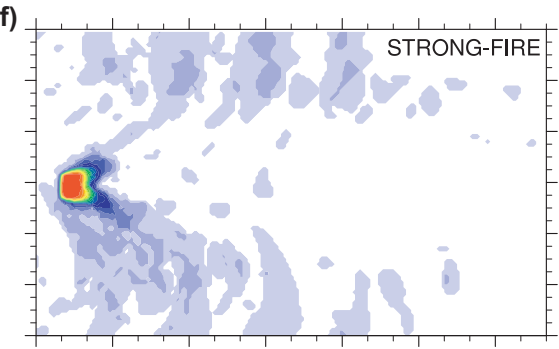

(h)

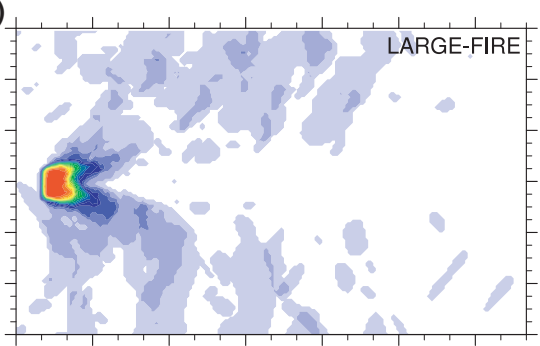

(i)

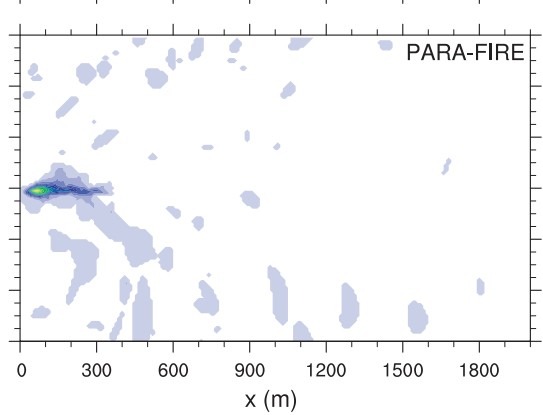

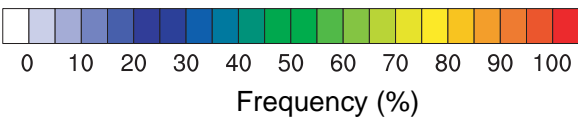

Figure 9. Spatial distribution of areas where a typical threshold velocity $v_{\text {tres }}$ of $6 \mathrm{~m} \mathrm{~s}^{-1}$ is exceeded in the lowest model level. Shown is the frequency of occurrence of such wind velocities per grid cell. 
(a)
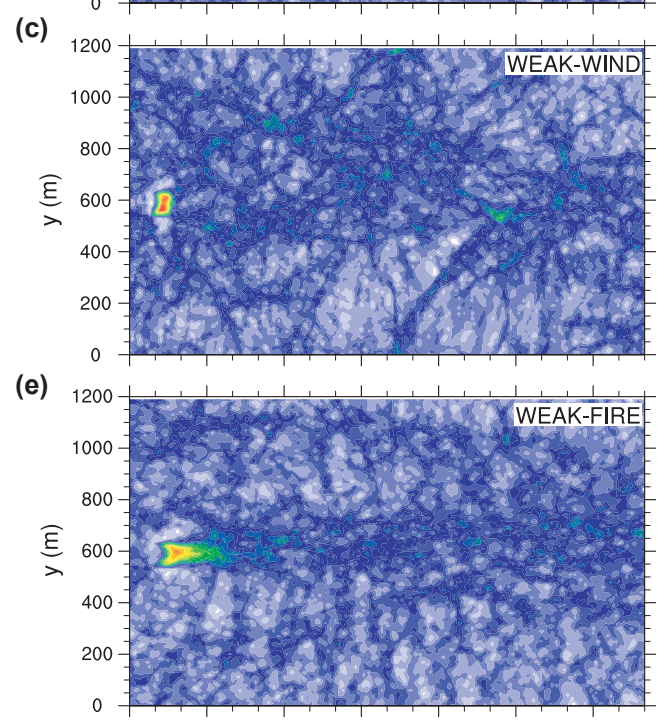

(g)
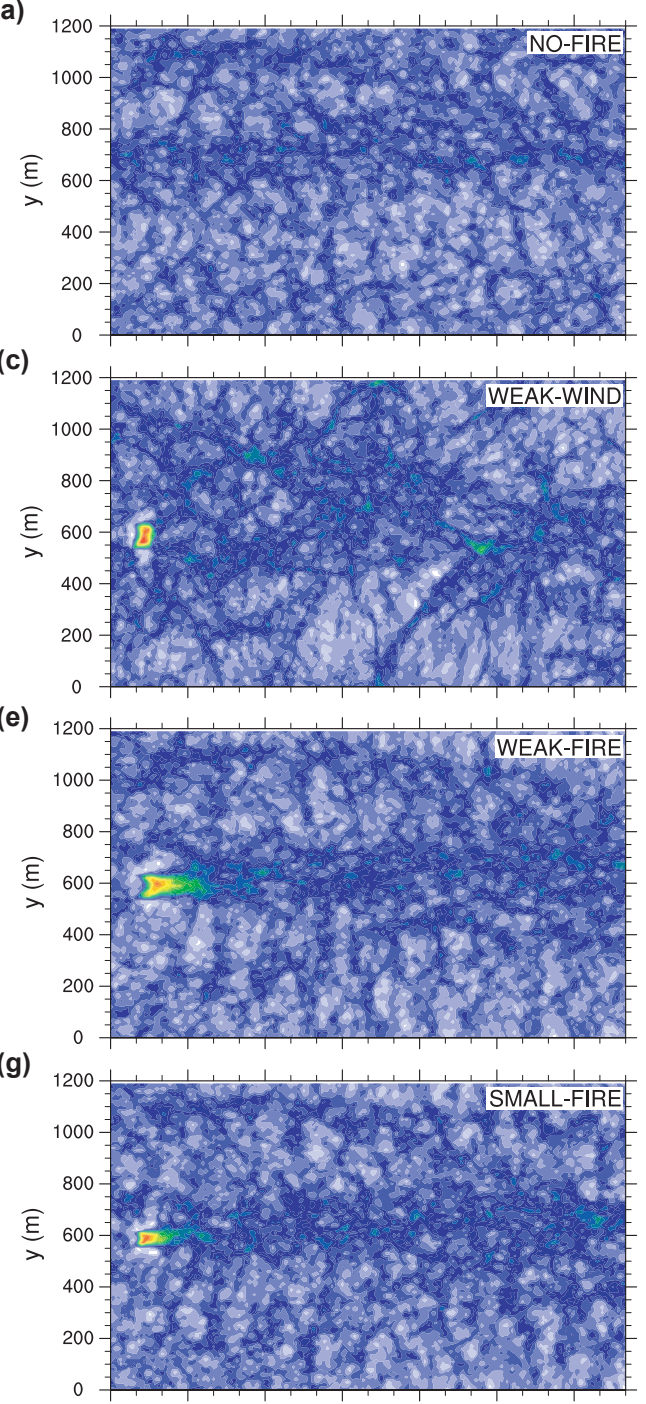

(i)

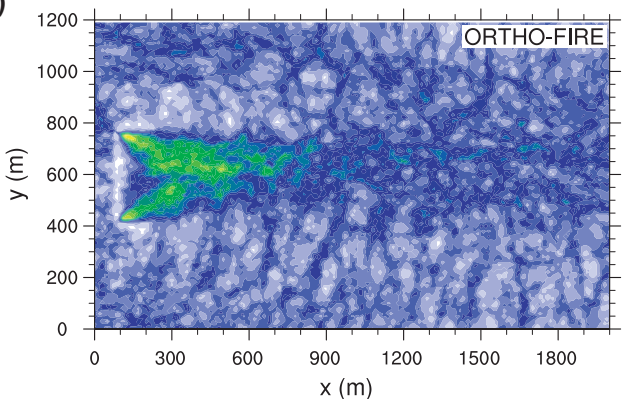

(b)

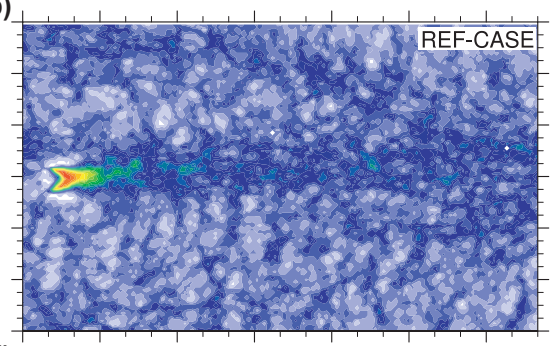

(d)

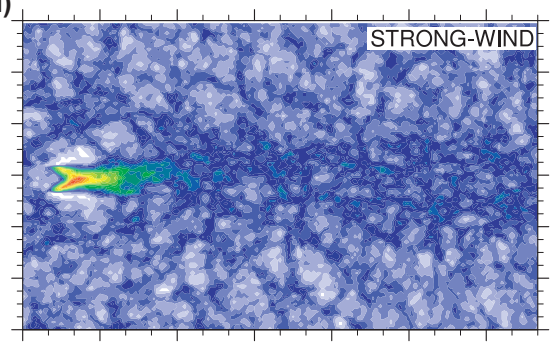

(f)

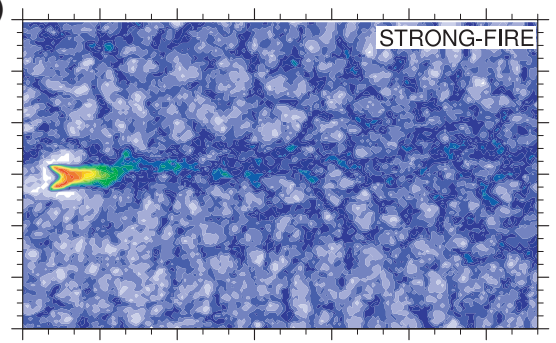

(h)

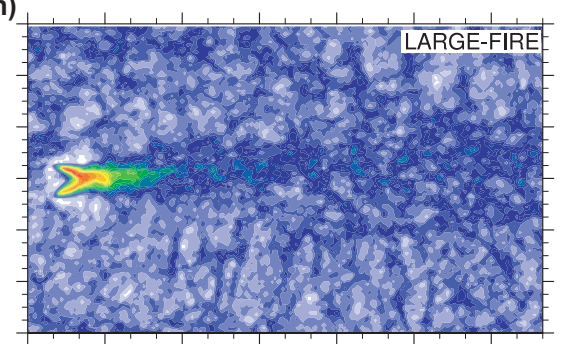

(j)

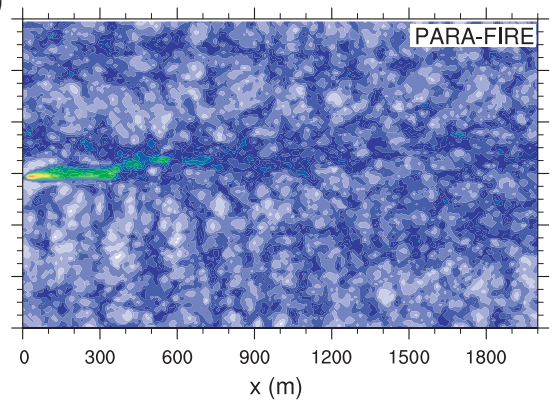

$$
\begin{array}{ccccccccccc}
0 & 10 & 20 & 30 & 40 & 50 & 60 & 70 & 80 & 90 & 100 \\
& & \multicolumn{7}{c}{\text { Frequency (\%) }}
\end{array}
$$

Figure 10. Spatial distribution of areas where the vertical wind velocity $w_{4}$ in the lowest model level is greater than $0.27 \mathrm{~m} \mathrm{~s}^{-1}$. Shown is the frequency of occurrence of such updraft velocities per grid cell. 
(a)

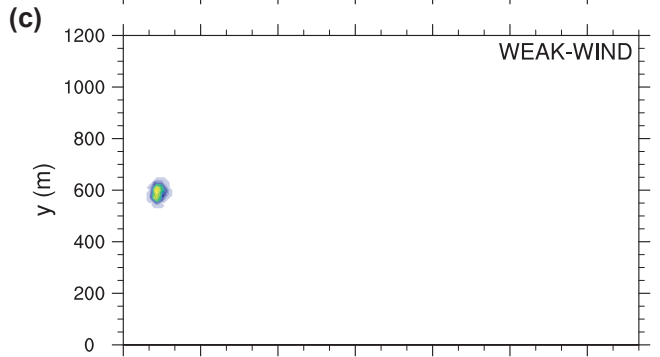

(e)

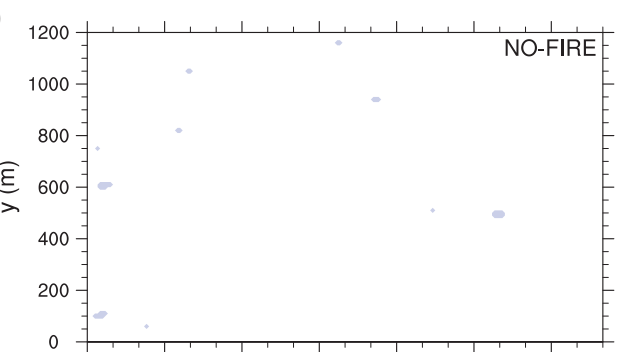

(c)

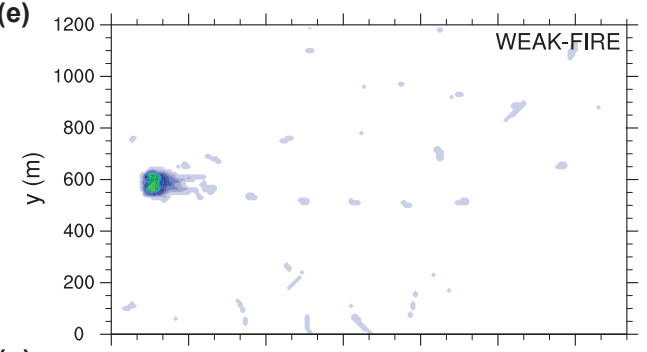

(g)

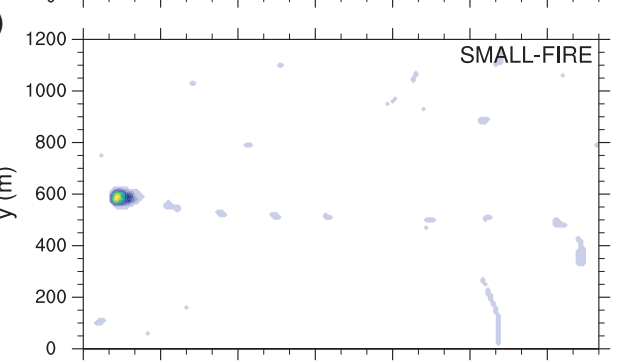

(i)

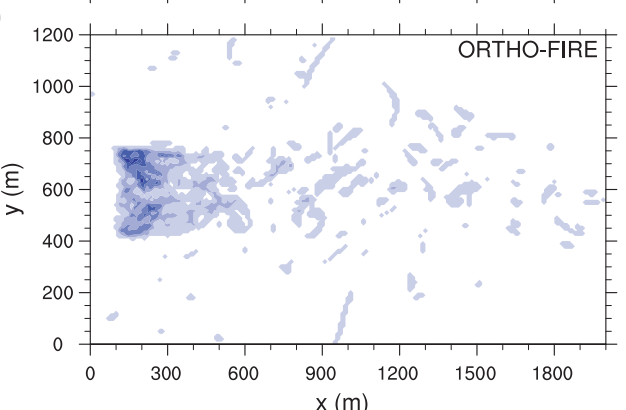

(b)

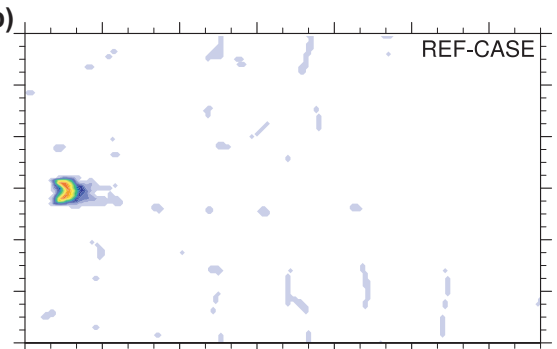

(d)

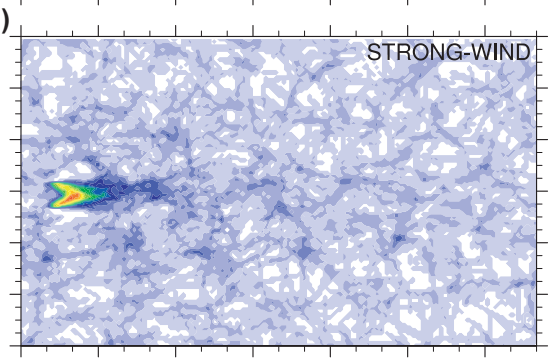

(f)

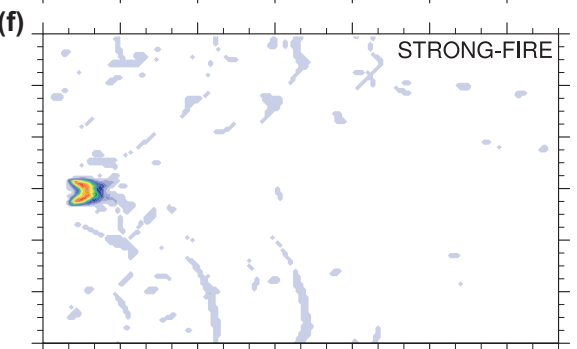

(h)

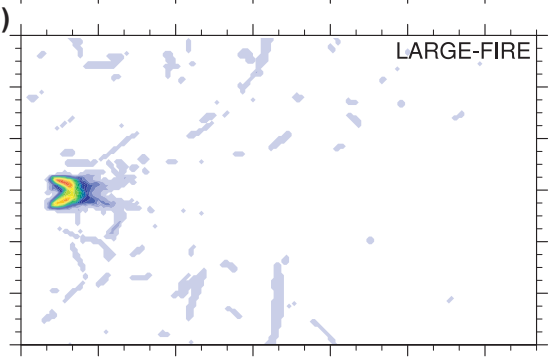

(j)

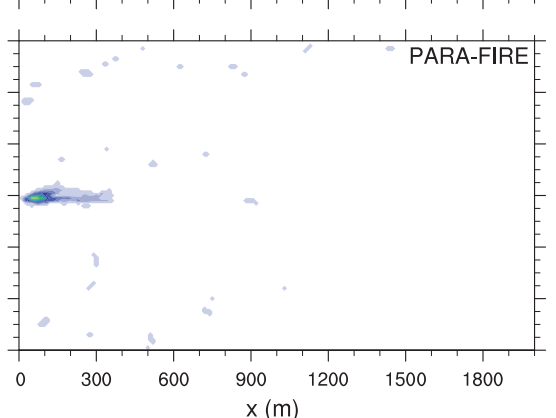

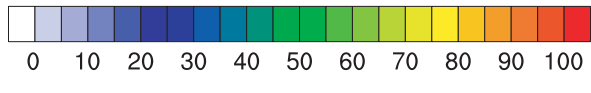

Frequency (\%)

Figure 11. Spatial distribution of areas where both the horizontal threshold velocity $v_{\text {tres }}=6 \mathrm{~m} \mathrm{~s}^{-1}$ (see Fig. 9) and a vertical wind velocity $w_{4}$ greater than $0.27 \mathrm{~m} \mathrm{~s}^{-1}$ (see Fig. 10) are exceeded at the same time. Shown is the frequency of occurrence of such events per grid cell. 
the atmosphere, although under some circumstances already lower horizontal wind velocities can be linked to a direct particle injection. However, here we will focus mainly on the dust emission potential with respect to the saltation process, which requires a higher horizontal threshold velocity.

The probabilities of the occurrence of simultaneous incidences of a horizontal wind velocity above $6 \mathrm{~m} \mathrm{~s}^{-1}$ and an updraft velocity $w_{1}-w_{5}$ for the chosen particle diameters are given in Table 3 for all case simulations. Exemplarily, for a particle diameter of $d_{4}=76 \mu \mathrm{m}$, the spatial distribution of the frequency of occurrence of the vertical velocity $w_{4}>0.27 \mathrm{~m} \mathrm{~s}^{-1}$ in the lowest model level at $z=5 \mathrm{~m}$ is shown in Fig. 10 and the corresponding overlap with areas where the horizontal threshold velocity is exceeded as well (Fig. 9) is given in Fig. 11. As visible in the NO-FIRE simulation (Fig. 10a), such an updraft velocity $w_{4}$ occurs for nearly every grid cell with a frequency of 5-30\% already without any fire influence. However, the impact of the fire leads in general to a significant increase in the occurrence of such updraft velocities up to $100 \%$ directly above and in front of the fire area. Zones in which nearly no updrafts developed can be identified at the flanks and upstream of the fire area. Here, the corresponding downdrafts, which are accelerated in horizontal near-surface winds and finally merged in the fire updrafts, dominate. Clearly visible is also the formation of an area of enhanced updraft occurrences within some hundreds of meters up to $1 \mathrm{~km}$ downstream of the fire area, most pronounced again in the ORTHO-FIRE simulation, related to the downstream transport of fire-generated turbulence by the forcing of the ambient winds.

By combining these regions with the areas of a threshold velocity $v_{\text {tres }}>6 \mathrm{~m} \mathrm{~s}^{-1}$, the fraction of suitable zones decreases significantly (Fig. 11). For the majority of the cases, now only the immediate fire area remains, to a large extent, suitable for the injection of dust particles of the given size of $d_{4}=76 \mu \mathrm{m}$ into the atmosphere, whereas the intensity and extent of such areas depend again mainly on the fire properties. Larger and more intense fires tend to have a much higher probability to mobilize and inject such dust particles compared to weaker and smaller fires. However, the behavior of the ORTHO-FIRE (Fig. 11i) stands out again, in particular concerning the suitable area of dust uplift. Although here no region with a constant high updraft velocity exists (Fig. 10i), the area where horizontal exceedances of the threshold velocity occur together with suitable updrafts extends up to $500 \mathrm{~m}$ ahead of the original fire line. In total, more than $9 \%$ of the grid cells within the leftmost $2 \mathrm{~km}$ of the domain are affected at least once by such a suitable combination, which is by far the highest value apart from the STRONG-WIND scenario. Since such line fires appear to represent a quite realistic scenario for agriculture-related grassland and cropland fires, the high coverage of possible regions acting as dust sources in a larger surrounding area of the fire is remarkable and would mean that the dust emission potential is drastically increased there, again under the assumption of suitable surface condi- tions favorable for dust mobilization (e.g., a bare or ploughed field).

In general, it can be concluded that a combination of sufficiently strong horizontal and vertical wind velocities occurs quite frequently, especially within and around the direct fire area, which means that the fire setups used in this study produce usually suitable conditions for the mobilization and injection of dust particles up to a size range of small sand particles. However, above the direct fire area the fire updrafts can reach such high velocities, which are strong enough that sand particles of a size of up to $1 \mathrm{~mm}$ or even larger could also be raised and injected into the atmosphere. Although these events are quite rare and limited to the direct fire area, for the majority of our scenarios such necessary updrafts with $w_{5}>5.1 \mathrm{~m} \mathrm{~s}^{-1}$ can be found occasionally (Table 3). Since the fire updrafts reach velocities of usually more than $10 \mathrm{~m} \mathrm{~s}^{-1}$ (see peak values in Table 3) in higher atmospheric levels (up to a height of roughly $1 \mathrm{~km}$ ), an injection of dust particles - reaching from small to large size ranges - into the PBL, and depending on the fire properties and PBL structures also into higher atmospheric levels, appears to be possible. Also, the rise of coarse-mode particles as was found in some studies (e.g., Radke, 1991; Nisantzi et al., 2014) can be explained quite well with the development of the strong fire-related horizontal and vertical winds. Once lifted from the surface, small dust particles with low sedimentation velocities in particular can be further distributed by larger- or synoptic-scale processes and interact with the atmospheric properties. However, this topic remains for further investigation and is not tackled by the setup of this study.

\section{Conclusions}

The conceptual model of how wildfires can act as a source of mineral dust particles emitted into the atmosphere has been presented and tested within this study. To analyze the impacts of the pyro-convection mechanism on the near-surface wind patterns in an already turbulent PBL, a large-eddy simulation (LES) with the All Scale Atmospheric Model (ASAM) was performed. In total, nine different model setups were applied to describe varying ambient meteorological wind conditions as well as fire properties representing typical grassland and shrubland fires in order to investigate the impacts concerning their ability to mobilize and raise mineral dust particles.

The simulations have shown that the energy released by the fires strongly modulates the near-surface wind patterns. The rising air of the fire updraft is related to an evolution of a zone of strong confluence within or slightly downstream of the fire area. Thus, horizontal near-surface winds are accelerated significantly and peak in wind velocities, which are much more intense compared to non-fire conditions. Especially within the direct fire area, the fire-driven nearsurface winds of our setups can reach values of up to $5 \mathrm{~m} \mathrm{~s}^{-1}$ higher compared to normal fluctuations within the modeled 
PBL. Assuming a commonly used threshold wind velocity of $6 \mathrm{~m} \mathrm{~s}^{-1}$ necessary to mobilize dust particles via saltation, it was found that such a value is frequently exceeded within and near the fire area. On the basis of suitable surface conditions at least within the fire area (removal of vegetation, soil modification) to allow dust emission, these fire-related winds supply the opportunity to mobilize dust particles. In interaction with the fire updraft, which provides the necessary upward motion to lift dust particles to higher atmospheric levels, it was shown that wildfires can increase the dust emission potential drastically as depicted by the conceptual model and should be taken into account as a source of airborne mineral dust.

To what extent such fires are able to mobilize and raise dust particles depends primarily on the fire properties such as fire size, intensity, and shape, and, secondly, also on the ambient wind velocities. Both impact the strength and frequency of occurrence of the peak wind velocities and the dust emission potential, whereas the fire properties appear to be more effective by modulating the wind fields. However, the ambient wind forcing also plays a role. A stronger ambient wind increases the likelihood of exceeding the threshold velocity under already weaker fires since a small fire-related intensification of the wind patterns is already sufficient to exceed the threshold and mobilize dust particles. Nevertheless, the chosen setups of grass- and shrubland fires have always led to an exceedance of the typical threshold velocity of $6 \mathrm{~m} \mathrm{~s}^{-1}$. Despite the fact that larger and more intense fires are related to a more pronounced increase in the near-surface wind velocities, a quite important parameter appears to be the shape and orientation of a fire to the ambient wind direction. For example, a line fire orthogonal to the ambient flow direction leads to a much stronger downstream transport of the fire-induced turbulence compared to a more aggregated, e.g., rectangular shaped, fire of the same size. This increases the dust emission potential up to $1 \mathrm{~km}$ and more ahead of the actual fire area and might be able to activate non-fire-related dust sources, with suitable soil and surface conditions assumed.

As this study has shown, wildfires can have a strong potential for favoring the emission of mineral dust by modifying the near-surface winds. However, until now they are not considered to be a source of airborne dust in aerosol-climate models, which often show large uncertainties and discrepancies concerning the atmospheric dust load and its impacts. Thus, an implementation of the fire-related dust emission process in mesoscale atmosphere-aerosol models appears to be necessary to allow a more accurate estimation of the total atmospheric dust load and dust-associated impacts on radiation budget and cloud and precipitation formation processes, especially on larger scales. This can finally contribute to a reduction of the uncertainty in the aerosol-climate feedback, especially regarding the highly variable anthropogenic part, the main cause of wildfires. Since these models cannot directly resolve the small-scale fire-related turbulence, responsible for dust entrainment, a parameterization of this process is needed. Therefore, the results gained here can be used to derive a first relation between the fire properties and the resulting modulations of the wind speed distribution. This can be achieved via coupling them with a dust emission scheme to determine the strength of the fire-related dust fluxes, where both the emission processes via saltation and direct turbulent entrainment should be considered. To describe this process and the subsequent atmospheric fire-driven pathways as accurately as possible, additional information on basic fire properties (e.g., fire radiative power, fire size) and surface characteristics (e.g., soil type, vegetation cover) are required, which can be obtained from satellite products for wildfire monitoring and land cover maps. However, further investigations are needed before the process of fire-related dust emissions can be included in such large-scale aerosol models. Before reaching that ambitious long-term goal, a quantification of the amount of fire-related dust emissions via coupling of the LES fire winds with offline dust emission models will be the next step. As this is carried out, regional/small-scale test cases can be computed and validated against measurements to prove the accuracy of the approach.

Data availability. LES data are available upon request.

Author contributions. RW performed the LES simulations, performed the analysis, and wrote the paper. MJ provided support for the initialization of the LES runs, and KS provided advice and support throughout the process.

Competing interests. The authors declare that they have no conflict of interest.

Acknowledgements. Robert Wagner and Kerstin Schepanski acknowledge the Leibniz Association funding for the project "Dust at the interface - modelling and remote sensing". The authors would like to thank Oswald Knoth from TROPOS for his help to set up ASAM. We acknowledge the Center for Information Services and High Performance Computing (ZIH) of the Technische Universität Dresden (TU Dresden) for providing computing capacity. The authors thank the two anonymous reviewers for their useful help is improving the quality of the paper. The publication of this article was funded by the Open Access Publishing Fund of the Leibniz Association.

Edited by: Yves Balkanski

Reviewed by: two anonymous referees 


\section{References}

Albalasmeh, A. A., Berli, M., Shafer, D. S., and Ghezzehei, T. A.: Degradation of moist soil aggregates by rapid temperature rise under low intensity fire, Plant Soil, 362, 335-344, 2013.

Alves, C. A., Gonçalves, C., Pio, C. A., Mirante, F., Caseiro, A., Tarelho, L., Freitas, M. C., and Viegas, D. X.: Smoke emissions from biomass burning in a Mediterranean shrubland, Atmos. Environ., 44, 3024-3033, 2010.

Amiridis, V., Giannakaki, E., Balis, D. S., Gerasopoulos, E., Pytharoulis, I., Zanis, P., Kazadzis, S., Melas, D., and Zerefos, C.: Smoke injection heights from agricultural burning in Eastern Europe as seen by CALIPSO, Atmos. Chem. Phys., 10, 1156711576, https://doi.org/10.5194/acp-10-11567-2010, 2010.

Ansmann, A., Baars, H., Tesche, M., Müller, D., Althausen, D., Engelmann, R., Pauliquevis, T., and Artaxo, P.: Dust and smoke transport from Africa to South America: Lidar profiling over Cape Verde and the Amazon rainforest, Geophys. Res. Lett., 36, L11802, https://doi.org/10.1029/2009gl037923, 2009.

Atanassova, I. and Doerr, S. H., Changes in soil organic compound composition associated with heat-induced increases in soil water repellency, Eur. J. Soil Sci., 62, 516-532, 2011.

Bagnold, R. A.: The pysics of Blown Sand and Desert Dunes, Methuen, London, 265 pp., 1941.

Cachier, H., Liousse, C., Buat-Menard, P., and Gaudichet, A.: Particulate content of savanna fire emissions, J. Atmos. Chem., 22, 123-148, 1995.

Chalbot, M. C., Nikolich, G., Etyemezian, V., Dubois, D. W., King, J., Shafer, D., Gamboa da Costa, G., Hinton, J. F., and Kavouras, I. G.: Soil humic-like organic compounds in prescribed fire emissions using nuclear magnetic resonance spectroscopy, Environ. Pollut., 181, 167-171, 10.1016/j.envpol.2013.06.008, 2013.

Clark, T. L., Radke, L., Coen, J., and Middleton, D.: Analysis of small-scale convective dynamics in a crown fire using infrared video camera imagery, J. Appl. Meteorol., 38, 1401-1420, 1999.

Clements, C. B., Zhong, S., Goodrick, S., Li, J., Potter, B. E., Bian, X., Heilman, W. E., Charney, J. J., Perna, R., Jang, M., Lee, D., Patel, M., Street, S., and Aumann, G.: Observing the dynamics of wildland grass fires: Fireflux - a field validation experiment, B. Am. Meteorol. Soc., 88, 1369-1382, 2007.

Clements, C. B., Zhong, S., Bian, X., Heilman, W. E., and Byun, D. W.: First observations of turbulence generated by grass fires, J. Geophys. Res., 113, D22102, https://doi.org/10.1029/2008jd010014, 2008.

Coen, J., Mahalingam, S., and Daily, J.: Infrared imagery of crownfire dynamics during FROSTFIRE, J. Appl. Meteorol., 43, 12411259, 2004.

Coen, J. L., Cameron, M., Michalakes, J., Patton, E. G., Riggan, P. J., and Yedinak, K. M.: WRF-Fire: coupled weather-wildland fire modeling with the weather research and forecasting model, J. Appl. Meteorol. Clim., 52, 16-38, 2013.

Cunningham, P., and Linn, R. R.: Numerical simulations of grass fires using a coupled atmosphere-fire model: Dynamics of fire spread, J. Geophys. Res., 112, D05108, https://doi.org/10.1029/2006jd007638, 2007.

Diapouli, E., Popovicheva, O., Kistler, M., Vratolis, S., Persiantseva, N., Timofeev, M., Kasper-Giebl, A., and Eleftheriadis, K.: Physicochemical characterization of aged biomass burning aerosol after long-range transport to Greece from large scale wildfires in Russia and surrounding regions, Summer 2010, Atmos. Environ., 96, 393-404, 2014.

Frankman, D., Webb, B. W., Butler, B. W., Jimenez, D., Forthofer, J. M., Sopko, P., Shannon, K. S., Hiers, J. K., and Ottmar, R. D.: Measurements of convective and radiative heating in wildland fires, Int. J. Wildland Fire, 22, 157-167, 2013.

Gatebe, C. K., Ichoku, C. M., Poudyal, R., Roman, M. O., and Wilcox, E.: Surface albedo darkening from wildfires in northern sub-Saharan Africa, Environ. Res. Lett., 9, 065003, https://doi.org/10.1088/1748-9326/9/6/065003, 2014.

Gaudichet, A., Echalar, F., Chatenet, B., Quisefit, J. P., Malingre, G., Cachier, H., Buat-Menard, P., Artaxo, P., and Maenhaut, W.: Trace elements in tropical African savanna biomass burning aerosols, J. Atmos. Chem., 22, 19-39, 1995.

Gillette, D.: A wind tunnel simulation of the erosion of soil: Effect of soil texture, sandblasting, wind speed, and soil consolidation on dust production, Atmos. Environ., 12, 1735-1743, 1978.

Giovannini, G., Vallejo, R., Lucchesi, S., Bautista, S., Ciompi, S., and Llovet, J., Effects of land use and eventual fire on soil erodibility in dry Mediterranean conditions, Forest Ecol. Manag., 147, 15-23, 2001.

Hand, V. L., Capes, G., Vaughan, D. J., Formenti, P., Haywood, J. M., and Coe, H.: Evidence of internal mixing of African dust and biomass burning particles by individual particle analysis using electron beam techniques, J. Geophys. Res., 115, D13301, https://doi.org/10.1029/2009jd012938, 2010.

Haywood, J. M., Pelon, J., Formenti, P., Bharmal, N., Brooks, M., Capes, G., Chazette, P., Chou, C., Christopher, S., Coe, H., Cuesta, J., Derimian, Y., Desboeufs, K., Greed, G., Harrison, M., Heese, B., Highwood, E. J., Johnson, B., Mallet, M., Marticorena, B., Marsham, J., Milton, S., Myhre, G., Osborne, S. R., Parker, D. J., Rajot, J. L., Schulz, M., Slingo, A., Tanré, D., and Tulet, P.: Overview of the Dust and Biomass-burning Experiment and African Monsoon Multidisciplinary Analysis Special Observing Period-0, J. Geophys. Res., 113, D00C17, https://doi.org/10.1029/2008jd010077, 2008.

Hinds, W. C.: Aerosol technology: properties, behavior, and measurement of airborne particles. A Wiley-Interscience Publication John Wiley \& Sons, 504 pp., 1982.

Jähn, M., Knoth, O., König, M., and Vogelsberg, U.: ASAM v2.7: a compressible atmospheric model with a Cartesian cut cell approach, Geosci. Model Dev., 8, 317-340, https://doi.org/10.5194/gmd-8-317-2015, 2015.

Jähn, M., Muñoz-Esparza, D., Chouza, F., Reitebuch, O., Knoth, O., Haarig, M., and Ansmann, A.: Investigations of boundary layer structure, cloud characteristics and vertical mixing of aerosols at Barbados with large eddy simulations, Atmos. Chem. Phys., 16, 651-674, https://doi.org/10.5194/acp-16-651-2016, 2016.

Johnson, B. T., Heese, B., McFarlane, S. A., Chazette, P., Jones, A., and Bellouin, N.: Vertical distribution and radiative effects of mineral dust and biomass burning aerosol over West Africa during DABEX, J. Geophys. Res., 113, D00C12, https://doi.org/10.1029/2008jd009848, 2008.

Kalma, J. D., Speight, J. G., and Wasson, R. J.: Potential wind erosion in Australia: A continental perspective, Int. J. Climatol., 8, 411-428, 1988.

Kavouras, I. G., Nikolich, G., Etyemezian, V., DuBois, D. W., King, J., and Shafer, D.: In situ observations of soil minerals and organic matter in the early phases of 
prescribed fires, J. Geophys. Res.-Atmos., 117, D12313, https://doi.org/10.2019/2011JD017420, 2012.

Klose, M. and Shao, Y.: Stochastic parameterization of dust emission and application to convective atmospheric conditions, Atmos. Chem. Phys., 12, 7309-7320, https://doi.org/10.5194/acp12-7309-2012, 2012.

Klose, M. and Shao, Y.: Large-eddy simulation of turbulent dust emission, Aeolian Res., 8, 49-58, 2013.

Knoth, O. and Wensch, J.: Generalized split-explicit Runge-Kutta methods for the compressible Euler equations, Mon. Weather Rev., 142, 2067-2081, 2014.

Kok, J. F., Parteli, E. J. R., Michaels, T. I., and Karam, D. B.: The physics of wind-blown sand and dust, Rep. Prog. Phys., 75, 106901, https://doi.org/10.1088/0034-4885/75/10/106901, 2012.

Lareau, N. P. and Clements, C. B.: The Mean and Turbulent Properties of a Wildfire Convective Plume, J. Appl. Meteorol. Clim., 56, 2289-2299, 2017.

Levin, N., Levental, S., and Morag, H.: The effects of wildfires on vegetation cover and dune activity in Australia's desert dunes: a multisensor analysis, Int. J. Wildland Fire, 21, 459-4753, 2012.

Levin, Z., Ganor, E., and Gladstein, V.: The effects of desert particles coated with sulfate on rain formation in the eastern Mediterranean, J. Appl. Meteorol., 35, 1511-1523, 1996.

Linn, R. R., and Cunningham, P.: Numerical simulations of grass fires using a coupled atmosphere-fire model: Basic fire behavior and dependence on wind speed, J. Geophys. Res., 110, D13107, https://doi.org/10.1029/2004jd005597, 2005.

Loosmore, G. A. and Hunt, J. R.:. Dust resuspension without saltation, J. Geophys. Res.-Atmos., 105, 20663-20671, 2000.

Maenhaut, W., Salma, I., Cafmeyer, J., Annegarn, H. J., and Andreae, M. O., Regional atmospheric aerosol composition and sources in the eastern Transvaal, South Africa, and impact of biomass burning, J. Geophys. Res.-Atmos., 101, 23631-23650, 1996.

Marticorena, B. and Bergametti, G.: Modeling the atmospheric dust cycle: 1. Design of a soil-derived dust emission scheme, J. Geophys. Res.-Atmos., 100, 16415-16430, 1995.

Maudlin, L. C., Wang, Z., Jonsson, H. H., and Sorooshian, A.: Impact of wildfires on size-resolved aerosol composition at a coastal California site, Atmos. Environ., 119, 59-68, 2015.

McCluskey, C. S., DeMott, P. J., Prenni, A. J., Levin, E. J., McMeeking, G. R., Sullivan, A. P., Hill, T. C. J., Nakao, S., Carrico, C. M., and Kreidenweis, S. M.: Characteristics of atmospheric ice nucleating particles associated with biomass burning in the US: Prescribed burns and wildfires, J. Geophys. Res.-Atmos., 119, 10458-10470, https://doi.org/10.1002/2014JD021980, 2014.

McNabb, D. H. and Swanson, F. J.: Effects of fire on soil erosion. Natural and prescribed fire in Pacific Northwest forests, edited by: Walstad, J., Radosevich, S., and Sandberg, D., Oregon State University Press, Corvallis, Oreg, 159-176, 1990.

Mell, W., Charney, J., Jenkins, M. A., Cheney, P., and Gould, J.: Numerical simulations of grassland fire behavior from the LANLFIRETEC and NIST-WFDS models, in: Remote Sensing and Modeling Applications to Wildland Fires, 209-225, Springer Berlin Heidelberg, 2008.

Merino-Martín, L., Field, J. P., Villegas, J. C., Whicker, J. J., Breshears, D. D., Law, D. J., and Urgeghe, A. M.: Aeolian sediment and dust fluxes during predominant "background" wind condi- tions for unburned and burned semiarid grassland: Interplay between particle size and temporal scale, Aeolian Res., 14, 97-103, 2014.

Morvan, D.: Physical phenomena and length scales governing the behaviour of wildfires: a case for physical modelling, Fire Technol., 47, 437-460, 2009.

Nisantzi, A., Mamouri, R. E., Ansmann, A., and Hadjimitsis, D.: Injection of mineral dust into the free troposphere during fire events observed with polarization lidar at Limassol, Cyprus, Atmos. Chem. Phys., 14, 12155-12165, https://doi.org/10.5194/acp-1412155-2014, 2014.

Palmer, T. Y.: Large fire winds, gases and smoke, Atmos. Environ., 15, 2079-2090, 1981.

Paris, R., Desboeufs, K. V., Formenti, P., Nava, S., and Chou, C.: Chemical characterisation of iron in dust and biomass burning aerosols during AMMA-SOP0/DABEX: implication for iron solubility, Atmos. Chem. Phys., 10, 4273-4282, https://doi.org/10.5194/acp-10-4273-2010, 2010.

Pérez-Cabello, F., de la Riva Fernández, J., Montorio Llovería, R., and García-Martín, A.: Mapping erosion-sensitive areas after wildfires using fieldwork, remote sensing, and geographic information systems techniques on a regional scale, J. Geophys. Res.Biogeo., 111, G04S10, https://doi.org/10.1029/2005jg000148, 2006.

Pio, C. A., Legrand, M., Alves, C. A., Oliveira, T., Afonso, J., Caseiro, A., Puxbaum, H., Sanchez-Ochoa, A., and Gelencsér, A.: Chemical composition of atmospheric aerosols during the 2003 summer intense forest fire period, Atmos. Environ., 42, 7530 7543, 2008.

Radke, L. F., Hegg, D. A., Hobbs, P. V., Nance, J. D., Lyons, J. H., Laursen, K. K., Weiss, R. E., Riggan, P. J., and Ward, D. E.: Particulate and trace gas emissions from large biomass fire in North America, in: Global Biomass Burning: Atmospheric, Climatic, and Biospheric Implications, edited by: Levine, J. S., The MIT Press, Cambridge, Massachusetts, 209-216, 1991.

Ravi, S., Baddock, M. C., Zobeck, T. M., and Hartman, J.: Field evidence for differences in post-fire aeolian transport related to vegetation type in semiarid grasslands, Aeolian Res., 7, 3-10, 2012.

Reid, J. S., Koppmann, R., Eck, T. F., and Eleuterio, D. P.: A review of biomass burning emissions part II: intensive physical properties of biomass burning particles, Atmos. Chem. Phys., 5, 799825, https://doi.org/10.5194/acp-5-799-2005, 2005.

Roberts, G., Wooster, M. J., and Lagoudakis, E.: Annual and diurnal african biomass burning temporal dynamics, Biogeosciences, 6 , 849-866, https://doi.org/10.5194/bg-6-849-2009, 2009.

Schlosser, J. S., Braun, R. A., Bradley, T., Dadashazar, H., MacDonald, A. B., Aldhaif, A. A., Aghdam, M. A., Mardi, A. H., Peng, X., and Sorooshian, A.: Analysis of aerosol composition data for western United States wildfires between 2005 and 2015: Dust emissions, chloride depletion, and most enhanced aerosol constituents; J. Geophys. Res.-Atmos., 122, 8951-8966, 2017.

Shao, Y.: A model for mineral dust emission, J. Geophys. Res.Atmos., 106, 20239-20254, 2001.

Sun, R., Krueger, S. K., Jenkins, M. A., Zulauf, M. A., and Charney, J. J.: The importance of fire-atmosphere coupling and boundarylayer turbulence to wildfire spread, Int. J. Wildland Fire, 18, 5060, 2009. 
Susott, R. A., Ward, D. E., Babbitt, R. E., and Latham, D. J.: The measurement of trace emissions and combustion characteristics for a mass fire, in: Global biomass buring: Atmospheric, climatic, and biosphere implications, edited by: Levine, J. S., Cambridge, MA, MIT Press, 245-257, 1991.

Tegen, I. and Fung, I.: Modeling of mineral dust in the atmosphere: Sources, transport, and optical thickness, J. Geophys. Res.-Atmos., 99, 22897-22914, 1994.

Tegen, I., Schepanski, K., and Heinold, B.: Comparing two years of Saharan dust source activation obtained by regional modelling and satellite observations, Atmos. Chem. Phys., 13, 2381-2390, https://doi.org/10.5194/acp-13-2381-2013, 2013.

Veira, A., Kloster, S., Wilkenskjeld, S., and Remy, S.: Fire emission heights in the climate system - Part 1: Global plume height patterns simulated by ECHAM6-HAM2, Atmos. Chem. Phys., 15, 7155-7171, https://doi.org/10.5194/acp-15-7155-2015, 2015.
Wagner, R., Schepanski, K., Heinold, B., and Tegen, I.: Interannual variability in the Saharan dust source activationToward understanding the differences between 2007 and 2008, J. Geophys. Res.-Atmos., 121, 4538-4562, https://doi.org/10.1002/2015jd024302, 2016.

Whicker, J. J., Breshears, D. D., Wasiolek, P. T., Kirchner, T. B., Tavani, R. A., Schoep, D. A., and Rodgers, J. C.: Temporal and spatial variation of episodic wind erosion in unburned and burned semiarid shrubland, J. Environ. Qual., 31, 599-612, 2002.

Whicker, J. J., Pinder, J. E., and Breshears, D. D.: Increased wind erosion from forest wildfire: Implications for contaminantrelated risks, J. Environ. Qual., 35, 468-478, 2006.

Winton, V. H. L., Edwards, R., Bowie, A. R., Keywood, M., Williams, A. G., Chambers, S. D., Selleck, P. W., Desservettaz, M., Mallet, M. D., and Paton-Walsh, C.: Dry season aerosol iron solubility in tropical northern Australia, Atmos. Chem. Phys., 16, 12829-12848, https://doi.org/10.5194/acp-16-128292016, 2016. 